\title{
Implementation of feedback-linearization-modelled induction motor drive through an adaptive simplified neuro-fuzzy approach
}

\author{
RABI NARAYAN MISHRA* and KANUNGO BARADA MOHANTY \\ Department of Electrical Engineering, National Institute of Technology Rourkela, Rourkela 769008, India \\ e-mail: rabimishra2014@gmail.com
}

MS received 30 December 2016; revised 11 March 2017; accepted 7 May 2017; published online 27 November 2017

\begin{abstract}
A simple modified version of neuro-fuzzy controller (NFC) method based on single-input, reduced membership function in conjunction with an intuitive flux-speed decoupled feedback linearization (FBL) approach of induction motor (IM) model is presented in this paper. The proposed NFC with FBL remarkably suppresses the torque and speed ripple and shows improved performance. Further, the modified NFC is tuned by genetic algorithm (GA) approach for optimal performance of FBL-based IM drive. Moreover, the GA searches the optimal parameters of the simplified NFC in order to ensure the global convergence of error. The proposed simplified NFC integrates the concept of fuzzy logic and neural network structure like a conventional NFC, but it has the advantages of simplicity and improved computational efficiency over the conventional NFC as the single input introduced here is an error (speed and torque) instead of two inputs, error and change in error, as in the conventional NFC. This structure makes the proposed NFC robust and simple as compared with conventional NFC and thus, can be easily applied to real-time industry application. The proposed system incorporated with different control methods is also validated with extensive experimental results using DSP2812. The effectiveness of the proposed method using FBL of IM drive is investigated in simulation as well as in experiment with different working modes. It is evident from the comparative results that the system performance is not deteriorated using the proposed simple NFC as compared to the conventional NFC; rather, it shows superior performance over PI-controller-based drive.
\end{abstract}

Keywords. Feedback linearization; induction motor; neuro-fuzzy controller; stationary reference frame.

\section{Introduction}

The promising implementation of nonlinear control [1] in the induction motor (IM) drive has been evolving as an emerging area of investigation work. Throughout the years, IMs have been widely utilized in various industries because of their minimal effort, simple structure, consistency and simplicity of use in an unpredicted condition with less maintenance. However, the control approach is complex due to its nonlinear dynamics, and parameter sensitivity in various working modes. Thus, an attempt has been made to implement an intuitive feedback-linearized IM drive by simplifying the structure of the controller. Further, the feedback-linearized IM control technique is sensitive to parameter variations and plant uncertainties, which motivate designing a robust modified neuro-fuzzy control scheme for overcoming these challenges in real world application of IM drive. The proposed simplified neurofuzzy controller (NFC) incorporated with feedback linearization (FBL)-based IM drive for enhancing the performance is the main contribution of this research work.

*For correspondence
Many attempts have been made earlier to upgrade the performance of IM drive through different control techniques like field-oriented control (FOC) [2,3]. This, in fact, has a significant impact on industrial applications by replacing costly, heavy DC motor drive. However, FOC methods require many transformations and the implementation of controllers is very difficult as the decoupling behaviour is obtained by proper state coordinates selection under the assumption of constant rotor flux. This leads to asymptotic decoupling of rotor flux and torque. Further, the decoupling is not completely obtained in the higher speed zone when the flux gets weakened [4]. This has led to nonlinear differential geometric control theory [5].

The differential geometric control recommended by Krezminski [6] is based on a multi-scalar motor model where static state feedback controller decouples the rotor torque and flux completely by selecting new state variables, which are different than that of FOC. In the articles [7-9], it was depicted that systems with multi-input can be made static feedback linearizable from input to state when an extra integrator is introduced to one of the inputs. This approach was considered in [8], where an IM model is made feedback linerizable by converting fifth-order IM 
state space model to a sixth-order model. However, this has certain constraints that make FBL dynamically infeasible. One of these is that when the motor torque is zero, feedback linearizing transformation is singular; to avoid this singularity, the control structure needs to be switched between two distinct transformations. Hence, to overcome this, a single dynamic FBL is proposed in [9], where one control quantity is transformed into two linearization schemes. This is done by approaching IM in $d-q$ coordinate system rather than $a-b$ coordinates.

In $[10,11]$, the decoupling of torque and flux control of current-controlled IM is obtained by two nonlinear feedback controllers. This is mainly based on input-output linearization of the nonlinear system through dynamic state feedback control. Again, the control performance of the drive system may not be so good as it is sensitive to load disturbance and detuned parameters, which were observed from the sensitivity analysis as in [11]. In the feedbacklinearized IM drives the problem of coupling is effectively sorted out, causing quick dynamic response. However, they are very much sensitive to parameter and plant uncertainties, external disturbance, etc. This leads to incorporation of different controllers with the FBL-controlled IM drive.

In recent years, significant research has been reported for improving control performance using fuzzy logic controller (FLC) [12, 13], sliding mode controller (SMC) $[1,14,15]$ and neural network controller [16]. The classical PI controller incorporated with FBL-controlled IM drive $[4,5,7,17]$ has the disadvantages of steady-state ripple, decoupling of flux and torque affected by parametric uncertainties, and load perturbation with poor dynamic response. To encounter these problems, SMC-based feedback-linearized IM drive has been introduced effectively in [18], which exhibits robust performance with system uncertainties. However, the chattering effect due to switching control law is introduced in the system response $[19,20]$. These issues can be fixed by applying smart control approaches $[16,21,22]$ as the controllers are constructed using human experience while handling the IM in every working mode and thereby, making the system robust and independent of system model dynamics.

The FLC has the drawbacks of poor stability and uncertainty [23, 24]. Also, an optimal FLC cannot be figured out by trial and error. On the other hand, it is very tough to acquire the training data for every working state of IM drive in artificial neural network (ANN) [25]. Consequently, the adaptive neuro-fuzzy hybrid intelligent system builds up a more effective system, which overcomes the drawbacks of FLC and ANN and generates optimized rules for the controller [21, 26-29]. In spite of adequate advantages of this intelligent hybrid controller, various industries have still not accepted these controllers for commercial purpose because of the high computational problem requiring a large number of membership functions (MFs), weights and rules, exclusively on auto-tuning condition [30]. Low sampling frequency due to this high computational burden is not acceptable for real-time application as it shows some overrun error. Moreover, low sampling rate leads to a large torque ripple in the case of the two-input conventional NFC. In addition, a fast processor may be required for these highcomputational-control algorithms, which is a costly affair and major concern for the industries.

This proposed work incorporates a suitable robust, simplified single-input and three-MF-based hybrid NFC technique combined with an intuitive feedback-linearized IM drive, which is implemented to improve the performance of the drive system. The intuitive FBL based on speed-flux linearization control is different from that of $[8-11,31]$ and simple. Thus, it simplifies the designing of the controller. The proposed NFC decreases the computational weight by reducing the MFs and rules when compared with conventional two-input NFC, which requires more number of MFs and rules. It is observed that the proposed NFC does not change the system execution unexpectedly for every single working state of IM drive when contrasted with conventional NFC; rather it upgrades and improves overall performance over the conventional PI controller.

The combination of two strategies preserves fast response and robust performance of conventional NFCbased linearized IM drive. Additionally, it remarkably reduces the torque and speed ripple and improves the system dynamic as well as steady-state performance. The outputs of PI-flux controller, NFC and rotor $d-q$ flux components estimated from voltage model [2] are inputs to the decoupling FBL controller. The signal generated from decoupling FBL controller is fed to a hysteresis current controller [32] to produce the required gate pulses for PWM voltage source inverter, which tracks motor reference current to produce desired torque. This approach starts with the FBL of an IM model in the $d-q$ stationary reference frame.

\section{Design of FBL of IM drive}

FBL control is an approach that can be implemented efficiently on nonlinear systems. This contrasts absolutely from conventional linearization frameworks as this linearization technique is applicable globally, rather than over a neighbourhood of an equilibrium point [1]. The input-output FBL is distinguished by a specific state coordinate change. Thus, it uses a nonlinear transformation of system variables to another appropriate coordinate system that facilitates FBL. The theoretical approach and a detailed methodology are given in [1].

The following equations characterize the dynamic mathematical modelling of IM drive fed by hysteresis band current-controlled PWM inverter in the $d-q$ stationary reference frame [17]:

$$
\begin{aligned}
\frac{d i_{d s}}{d t}= & -\frac{1}{\sigma L_{s}}\left(R_{s}+\frac{L_{m}^{2}}{L_{r}^{2}} R_{r}\right) i_{d s}+\frac{1}{\sigma L_{s}} \frac{L_{m} R_{r}}{L_{r}^{2}} \psi_{d r} \\
& +\frac{P L_{m}}{\sigma L_{s} L_{r}} \omega_{r} \psi_{q r}+\frac{V_{d s}}{\sigma L_{s}}
\end{aligned}
$$




$$
\begin{gathered}
\frac{d i_{q s}}{d t}=-\frac{1}{\sigma L_{s}}\left(R_{s}+\frac{L_{m}^{2}}{L_{r}^{2}} R_{r}\right) i_{q s}+\frac{1}{\sigma L_{s}} \frac{L_{m} R_{r}}{L_{r}^{2}} \psi_{q r} \\
-\frac{P L_{m}}{\sigma L_{s} L_{r}} \omega_{r} \psi_{d r}+\frac{V_{q s}}{\sigma L_{s}} \\
\frac{d \psi_{d r}}{d t}=-\frac{R_{r}}{L_{r}} \psi_{d r}-P \omega_{r} \psi_{q r}+\frac{L_{m} R_{r}}{L_{r}} i_{d s} \\
\frac{d \psi_{q r}}{d t}=-\frac{R_{r}}{L_{r}} \psi_{q r}+P \omega_{r} \psi_{d r}+\frac{L_{m} R_{r}}{L_{r}} i_{q s} \\
\frac{d \omega_{r}}{d t}=-\frac{B}{J} \omega_{r}+\frac{1}{J}\left(T_{e}-T_{l}\right)
\end{gathered}
$$

where $Y^{T}$ is the $m \times 1$ system output vector; $\omega_{r}$ and $\psi_{r}$ are the rotor speed and flux, respectively.

The nonlinear state space equation for this multivariable system $[1,5]$ can be written as

$\dot{X}=f(x)+\sum_{i=1}^{m} g_{i}(x) \hat{u}_{i} \quad$ and $\quad Y_{i}=h_{i}(x) \quad$ for $1 \leq i \leq m$.

Then, as per the IM modelling equations (1)-(6)

$$
f(x)=\left[\begin{array}{c}
-\frac{1}{\sigma L_{s}}\left(R_{s}+\frac{L_{m}^{2}}{L_{r}^{2}} R_{r}\right) i_{d s}+\frac{1}{\sigma L_{s}} \frac{L_{m} R_{r}}{L_{r}^{2}} \psi_{d r}+\frac{P L_{m}}{\sigma L_{s} L_{r}} \omega_{r} \psi_{q r}+\frac{V_{d s}}{\sigma L_{s}} \\
-\frac{1}{\sigma L_{s}}\left(R_{s}+\frac{L_{m}^{2}}{L_{r}^{2}} R_{r}\right) i_{q s}+\frac{1}{\sigma L_{s}} \frac{L_{m} R_{r}}{L_{r}^{2}} \psi_{q r}-\frac{P L_{m}}{\sigma L_{s} L_{r}} \omega_{r} \psi_{d r}+\frac{V_{q s}}{\sigma L_{s}} \\
-\frac{R_{r}}{L_{r}} \psi_{d r}-P \omega_{r} \psi_{q r} \\
-\frac{R_{r}}{L_{r}} \psi_{q r}+P \omega_{r} \psi_{d r} \\
-\frac{B}{J} \omega_{r}-\frac{1}{J} T_{l}
\end{array}\right]
$$

$$
T_{e}=\frac{3}{2} \frac{L_{m}}{L_{r}} P\left(\psi_{d r} i_{q s}-\psi_{q r} i_{d s}\right)
$$

where $V, i$ and $\Psi$ represent voltage, current and flux, respectively. The subscripts $d s, q s$ and $d r, q r$ correspond to the stator and rotor components along $d-q$ axes; $R_{s}$ and $R_{r}$ are the stator and rotor resistances; $L_{s}, L_{r}$ and $L_{m}$ are the stator, rotor and magnetizing inductances. $\sigma=\left(1-\frac{L_{m}^{2}}{L_{s} L_{r}}\right)$ is the leakage coefficient; $\omega_{r}, P, T_{e}, T_{l}, J$ and $B$ are the rotor speed, number of pole pairs, electromagnetic torque, load torque, rotor inertia coefficient and friction coefficient, respectively.

The nonlinear dynamics of IM considered here is of fifth order with the chosen state variables

$$
X^{T}=\left[\begin{array}{lllll}
i_{d s} & i_{q s} & \psi_{d r} & \psi_{q r} & \omega_{r}
\end{array}\right]
$$

and the input variables

$$
\hat{u}^{T}=\left[\begin{array}{ll}
\widehat{u 1} & \widehat{u 2}
\end{array}\right]=\left[\begin{array}{ll}
i_{d s} * & i_{q s} *
\end{array}\right]
$$

where $X$ is the $n \times 1$ state vector and $\hat{u}$ is the $m \times 1$ input control vector.

The controller output parameter should be so chosen that the IM behaves like a DC motor, making the rotor speed and flux decoupled. Therefore, output of control parameter should be chosen as

$$
Y^{T}=\left[h_{1}(x) \quad h_{2}(x)\right]=\left[\begin{array}{ll}
\omega_{r} & \psi_{r}
\end{array}\right]
$$

$$
\begin{gathered}
g_{1}(x)=\left[\begin{array}{lllll}
0 & 0 & \frac{L_{m}}{T_{r}} & 0 & -K_{T} \psi_{q r}
\end{array}\right]^{T} \text { and } \\
g_{2}(x)=\left[\begin{array}{lllll}
0 & 0 & 0 & \frac{L_{m}}{T_{r}} & K_{T} \psi_{d r}
\end{array}\right]^{T}
\end{gathered}
$$

where $K_{T}=\frac{1}{J} \frac{3}{2} \frac{L_{m}}{L_{r}} P$ and $T_{r}=\frac{L_{r}}{R_{r}}$ is known as the rotor time constant.

If $\psi_{d r}$ and $\psi_{q r}$ are considered as nonzero altogether, the relative degree of the system is $r=r_{1}+r_{2}=4$, provided it satisfies the involutive condition, which is the necessary condition for decoupling FBL control, i.e., the Lie bracket of $g_{1}(x)$ and $g_{2}(x)$ exists.

The Lie bracket of $g_{1}(x)$ and $g_{2}(x)$ is given as

$$
\left[g_{1}, g_{2}\right](x)=\frac{\partial g_{2}}{\partial x} g_{1}(x)-\frac{\partial g_{1}}{\partial x} g_{2}(x)=\frac{2 K_{T} L_{m}}{T_{r}} \neq 0 .
$$

Hence, it satisfies the involutive condition for the values of $P, L_{m}, R_{r}, J$ and $L_{r}$ that are mentioned in the Appendix.

Now the total rotor flux in terms of $d-q$ component is expressed as

$$
\psi_{r}^{2}=\psi_{d r}^{2}+\psi_{q r}^{2}
$$

and

$$
\frac{d \psi_{r}}{d t}=\frac{1}{\psi_{r}}\left(\psi_{d r} \frac{d \psi_{d r}}{d t}+\psi_{q r} \frac{d \psi_{q r}}{d t}\right) .
$$


When the current controller directly controls the stator currents, Eqs. (3), (4) and (5) of IM are given, respectively, by

$$
\begin{gathered}
\frac{d \psi_{d r}}{d t}=-\frac{R_{r}}{L_{r}} \psi_{d r}-P \omega_{r} \psi_{q r}+\frac{L_{m} R_{r}}{L_{r}} \widehat{u 1} \\
\frac{d \psi_{q r}}{d t}=-\frac{R_{r}}{L_{r}} \psi_{q r}+P \omega_{r} \psi_{d r}+\frac{L_{m} R_{r}}{L_{r}} \widehat{u 2} \\
\frac{d \omega_{r}}{d t}=-\frac{B}{J} \omega_{r}+\frac{1}{J} \frac{3}{2} \frac{L_{m}}{L_{r}} P\left(\widehat{u 2} \psi_{d r}-\widehat{u 1} \psi_{q r}\right)-\frac{1}{J} T_{l} .
\end{gathered}
$$

Substituting $\frac{d \psi_{d r}}{d t}$ and $\frac{d \psi_{q r}}{d t}$ from Eqs. (16) and (17) in Eq. (15), the linearized state space equations of rotor flux and speed are obtained as

$$
\begin{gathered}
\frac{d \psi_{r}}{d t}=-\frac{R_{r}}{L_{r}} \psi_{r}+\frac{L_{m} R_{r}}{L_{r}} u 1 \\
\frac{d \omega_{r}}{d t}=-\frac{B}{J} \omega_{r}+\frac{1}{J} \frac{3}{2} \frac{L_{m}}{L_{r}} P u 2-\frac{1}{J} T_{l}
\end{gathered}
$$

where $u 1$ and $u 2$ are considered as new control inputs that make state equations (16), (17), and (18) as feedback linearized, and are redefined as follows:

$$
\left[\begin{array}{l}
u 1 \\
u 2
\end{array}\right]=\left[\begin{array}{cc}
\frac{\psi_{d r}}{\psi_{r}} & \frac{\psi_{q r}}{\psi_{r}} \\
-\psi_{q r} & \psi_{d r}
\end{array}\right]\left[\begin{array}{l}
\widehat{u 1} \\
u 2
\end{array}\right]
$$

where the matrix $\left[\begin{array}{cc}\frac{\psi_{d r}}{\psi_{r}} & \frac{\psi_{q r}}{\psi_{r}} \\ -\psi_{q r} & \psi_{d r}\end{array}\right]$ is defined as a decoupling matrix $D(x)$. The matrix $D(x)$ is non-singular except in the trivial condition when the rotor flux is zero, which occurs during start-up of the motor. However, in the regular operation of the motor, this condition never happens in the practical drive as the flux is set up prior to starting the IM drive. Since the left plane poles are evident from the dynamics of $\omega_{r}$ and $\psi_{r}$, the closed-loop input-output stability of the remaining state variables can be assured provided the rotor flux has a nonzero value.

Equations (19) and (20) represent the IM with FBL, which is of second order, with rotor flux and speed as decoupled state variables. Consequently, the new model is intuitively linear and simplifies the designing of the controller. If the decoupling matrix is non-singular, the nonlinear state feedback controller obtained from Eq. (21), which decouples the system, is given by Eq. (22) and the block diagram of feedback-linearized controller is given in figure 1a:

$$
\left[\begin{array}{l}
\widehat{u 1} \\
\widehat{u 2}
\end{array}\right]=\left[\begin{array}{c}
i_{d s}^{*} \\
i_{q s}^{*}
\end{array}\right]=\frac{1}{\psi_{r}}\left[\begin{array}{cc}
\psi_{d r} & -\psi_{q r} \\
\psi_{q r} & \psi_{d r}
\end{array}\right]\left[\begin{array}{cc}
1 & 0 \\
0 & \frac{1}{\psi_{r}}
\end{array}\right]\left[\begin{array}{l}
u 1 \\
u 2
\end{array}\right]
$$

For stable error dynamics and exact tracking of target rotor flux and speed, the derived inputs $u 1$ and $u 2$ are the outputs of PI controller, which are given by

$$
\begin{aligned}
& u 1=K_{p 1}\left(\psi_{r} *-\psi_{r}\right)+K_{i 1} \int_{0}^{t}\left(\psi_{r} *-\psi_{r}\right) d t \\
& u 2=K_{p 2}\left(\omega_{r} *-\omega_{r}\right)+K_{i 2} \int_{0}^{t}\left(\omega_{r} *-\omega_{r}\right) d t
\end{aligned}
$$

Equations (19) and (20) define an electrical and mechanical system that has $\left(i_{d s} *, i_{q s} *\right)$ and $\left(\psi_{r}, \omega_{r}\right)$ as control inputs and outputs, respectively. Hence, it describes a framework that is coupled as the outputs and inputs are not directly related. Thus, the nonlinear control theory [1] is utilized to remove this coupled relation and makes the system inputs $i_{d s}, i_{q s}$ and the outputs $\psi_{r}, \omega_{r}$ totally decoupled. The feedback-decoupled system with Eqs. (19) and (23) is represented in the block diagram shown in figure $1 \mathrm{~b}$. Accurate estimation of flux is required for perfectly decoupling FBL control, which is evident from Eq. (22).

An estimation-based sensorless strategy is adapted based on a voltage model $[2,28]$, where the stator voltages and currents are sensed, and the flux is estimated in the $d-$ $q$ stationary reference frame.

From the model of IM drive, voltage equation in the $d-q$ stationary reference frame can be stated as

$$
V_{d s}=\left(R_{s}+\sigma L_{s} p\right) i_{d s}+\frac{L_{m}}{L_{r}} p \Psi_{d r}
$$

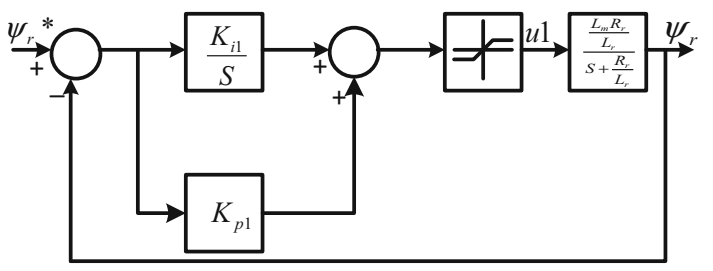

(b)

Figure 1. Block diagram of (a) decoupling feedback-linearized controller and (b) closed-loop decoupled system. 


$$
V_{q s}=\left(R_{s}+\sigma L_{s} p\right) i_{q s}+\frac{L_{m}}{L_{r}} p \Psi_{q r}
$$

where $p$ is the differential operator $\frac{d}{d t}$. The rotor torque and flux components can be obtained using Eqs. (6), (25) and (26).

The linearized model of IM formed by FBL technique is sensitive to parameter variations and plant uncertainties. As a result, a robust neuro-fuzzy control scheme is designed for confronting these challenges in the real-time application of IM drive.

\section{Design of neuro-fuzzy controllers}

The knowledge representation of FLC combined with the learning power of ANN system gives adaptive NFC. Since NFC design starts with a prestructured system, the level of flexibility for learning is inhibited, i.e., the input and output MFs comprise more information than what a neural system needs to get from test pair of data. Data concerning a system under an arrangement can be used right from the start. Some part of the system can be removed from training, thus making the process more effective. The intermediate results can be examined effortlessly as the rules are in linguistic form. NFC implements a first-order Sugeno fuzzy system as a result of its computational efficiency and versatile procedures $[2,22,33]$. To start NFC tuning, a training data pair that contains necessary input-output data set of the target system to be designed is required. The objective is picked taking into account the best response of the system. The proposed NFC-based feedback-linearized drive is illustrated in figure 2 .
However, some parameters of the NFC are still to be optimized as they get trapped in a local minimum solution. In this scenario, the field of metaheuristic plays an important role that is based on an approximation method [34-37]. The hybridization or integration of metaheuristics is, in fact, a growing research area due to its importance of combinatorial optimization problem applied to the industrial world [38, 39]. It supervises a subordinate heuristic by incorporating concepts based on artificial intelligence, mathematical, biological and nature-inspired science to enhance their performance. The concepts used in metaheuristic algorithms vary from local search methods to complex learning methods. Metaheuristics are also not problem-dependent methods. In NFC, the parameters of the fuzzy logic are optimized by learning algorithm of the ANN but, during this, the solution may fall in local minima. Thus, the fusion approach of NFC and GA encounters this problem by preserving the excellent learning algorithm by ANN and simultaneously, optimizing the antecedent parameters and learning rate by GA technique [40].

\subsection{Proposed simplified NFC}

The proposed simplified NFC (SNFC) design integrates FLC with a four-level ANN organization, as described in figure $3 \mathrm{a}$. The proposed NFC is modified by a simple control algorithm in order to achieve the required performance of the IM drive system. The parameter of the third layer is modified by tuning to control any deviation of control effort. The single-input speed error due to the difference of desired speed $\omega_{r}^{*}$ and the actual speed $\omega_{r}$ of the NFC is as follows:
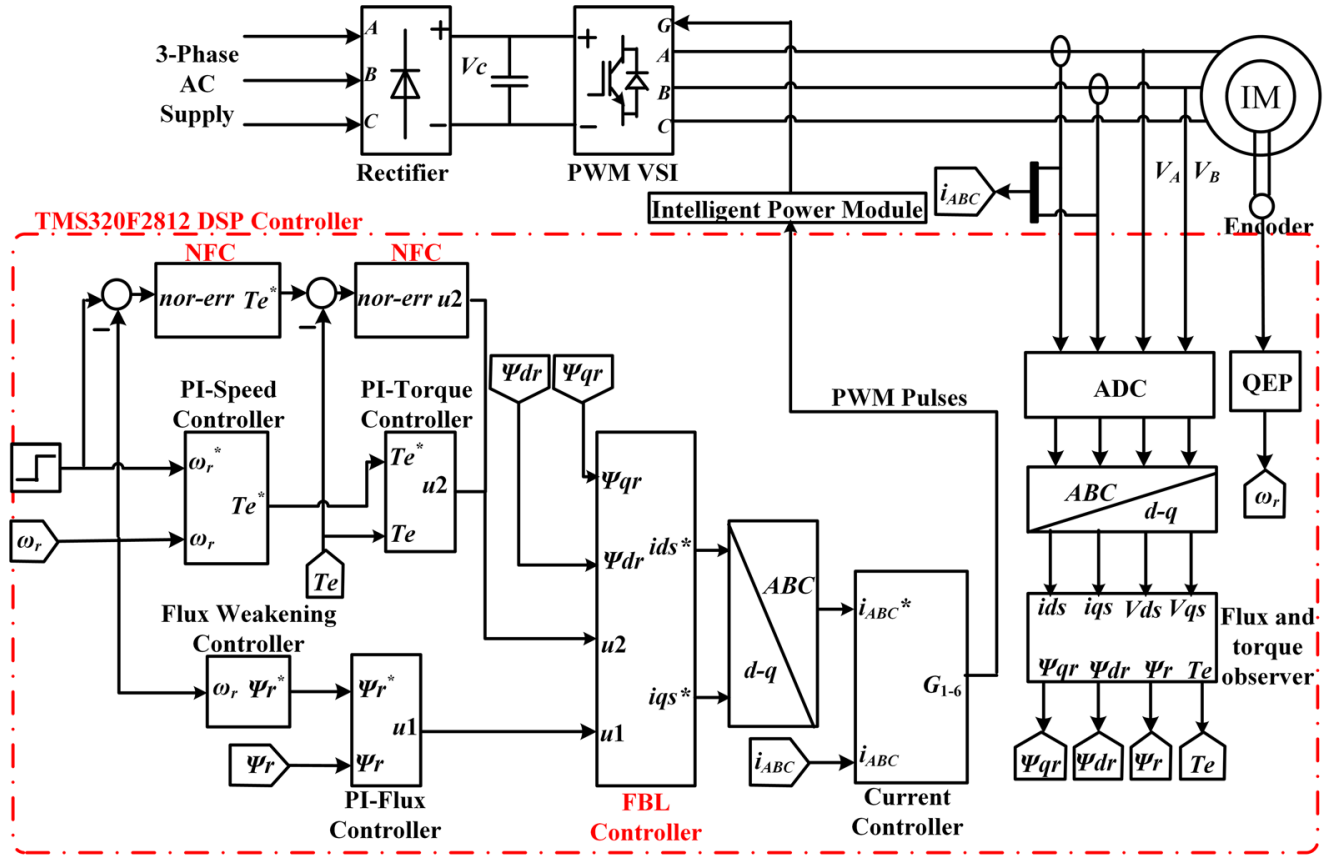

Figure 2. Proposed NFC-based induction motor using feedback linearization. 


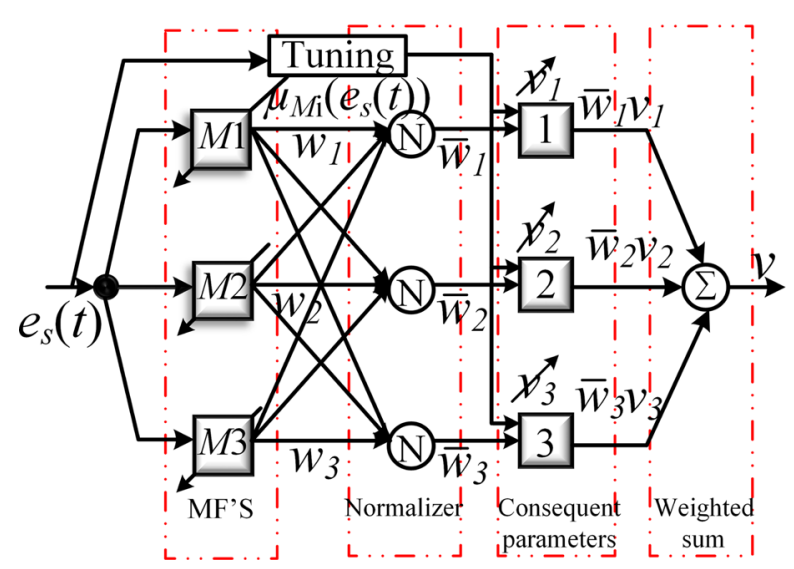

(a)

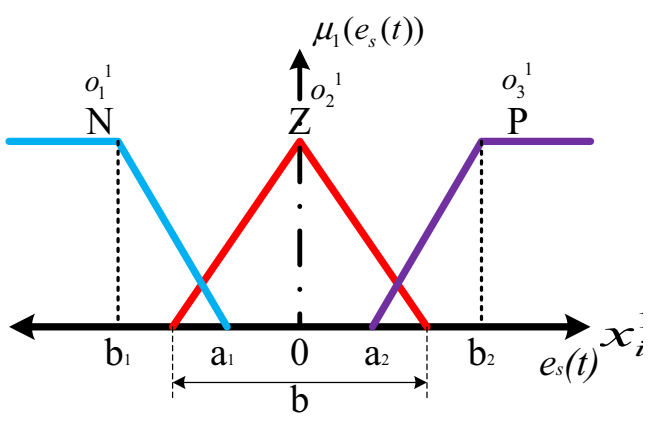

(b)

Figure 3. Neuro-fuzzy controller: (a) proposed modified architecture and (b) input MFs.

$$
\% e_{s}(t)=\frac{\omega_{r}^{*}-\omega_{r}}{\omega_{r}^{*}} \times 100 .
$$

Layer 1: The output equations of this fuzzification layer having adaptive nodes of three-speed error MFs as negative $(\mathrm{N})$, zero $(\mathrm{Z})$ and positive $(\mathrm{P})$ speed errors are given by

$$
\begin{gathered}
O_{1}^{1}=\mu_{M 1}\left(e_{s}(t)\right)=\left\{\begin{array}{cc}
1, & x_{i}^{1} \leq b_{1} \\
\frac{x_{i}^{1}-a_{1}}{b_{1}-a_{1}}, & b_{1}<x_{i}^{1}<a_{1} \\
0, & x_{i}^{1} \geq a_{1}
\end{array}\right. \\
O_{2}^{1}=\mu_{M 2}\left(e_{s}(t)\right)=\left\{\begin{array}{cc}
0, & \left|x_{i}^{1}\right| \geq \frac{b}{2} \\
1-\frac{2\left|x_{i}^{1}-a\right|}{b}, & \left|x_{i}^{1}-a\right| \leq \frac{b}{2}
\end{array}\right. \\
O_{3}^{1}=\mu_{M 3}\left(e_{s}(t)\right)=\left\{\begin{array}{cc}
0, & x_{i}^{1} \leq a_{2} \\
\frac{x_{i}^{1}-a_{2}}{b_{2}-a_{2}}, & a_{2}<x_{i}^{1}<b_{2} \\
1, & x_{i}^{1} \geq b_{2}
\end{array}\right.
\end{gathered}
$$

where $\mu_{M 1}\left(e_{s}(t)\right), \mu_{M 2}\left(e_{s}(t)\right), \mu_{M 3}\left(e_{s}(t)\right)$ are chosen to be symmetrical $(a=0)$ linear MFs as in figure $3 \mathrm{~b}$ rather than any exponential function in order to lessen the computational weight and make it more efficient. Here, $x$ and $O$ correspond to input and output, and their superscript and subscript denote layer and node number, respectively.

Layer 2: The 'AND' logic operator is not used in this layer for the calculation of the weight of rules $w_{i}$, since only one input is present here unlike conventional two-input NFC. The normalized $\overline{w_{i}}$ can be written as

$$
O_{i}^{2}=\overline{w_{i}}=\frac{w_{i}}{\sum_{i} w_{i}}, \quad i=1,2,3 .
$$

Layer 3: The consequent value $v_{i}$ is calculated in this layer as node equation, whose output is specified as

$$
O_{i}^{3}=\overline{w_{i}} v_{i}, \quad i=1,2,3 .
$$

Layer 4: This is the defuzzification layer, where the NFC output is determined by centre-of-gravity method and is specified as

$$
v=O_{i}^{4}=\frac{\sum_{i} w_{i} v_{i}}{\sum_{i} w_{i}}=\sum_{i} \overline{w_{i}} v_{i}, i=1,2,3 .
$$

\subsection{Two-input conventional NFC}

In order to make a fair performance comparison, the MFs of conventional NFC are chosen to be the same as those of the proposed NFC. The two inputs of this NFC are speed error and change in speed error, which are given by

$$
\begin{gathered}
\% e_{s}(t)=\frac{\omega_{r}^{*}-\omega_{r}}{\omega_{r}^{*}} \times 100 \\
\% \Delta e_{s}(t)=\frac{e_{s}(t)_{k}-e_{s}(t)_{k-1}}{T} \times 100
\end{gathered}
$$

where $T$ is the sampling time and $k$ is the sampling instant; $e_{s}(t)_{k}$ and $e_{s}(t)_{k-1}$ represent present and previous speed error, respectively.

The NFC structural design integrates fuzzy logic and learning algorithm with a five-level ANN arrangement [33] as depicted in figure $4 \mathrm{~b}$. In the proposed Sugeno fuzzy model [2] depicted in figure $4 \mathrm{a}$, the typical rule set with fuzzy rules can be expressed as

$$
\begin{aligned}
\text { rule } i(i=1,2,3) & : \text { if } e(t) \text { is } \mathrm{M}_{1 i} \text { AND } \Delta e(t) \text { is } \mathrm{M}_{2 i} \text { then } v_{i} \\
& =m_{1 i} e(t)+m_{2 i} \Delta e(t)+r_{i}
\end{aligned}
$$

where $\mathbf{M}_{1 i}$ and $\mathbf{M}_{2 i}$ are the antecedent fuzzy sets and $m_{1 i}$, $m_{2 i}$ and $r_{i}$ are the design parameters evaluated in training. Here, $v_{i}$ is the output singleton MF as shown in figure 4. In 


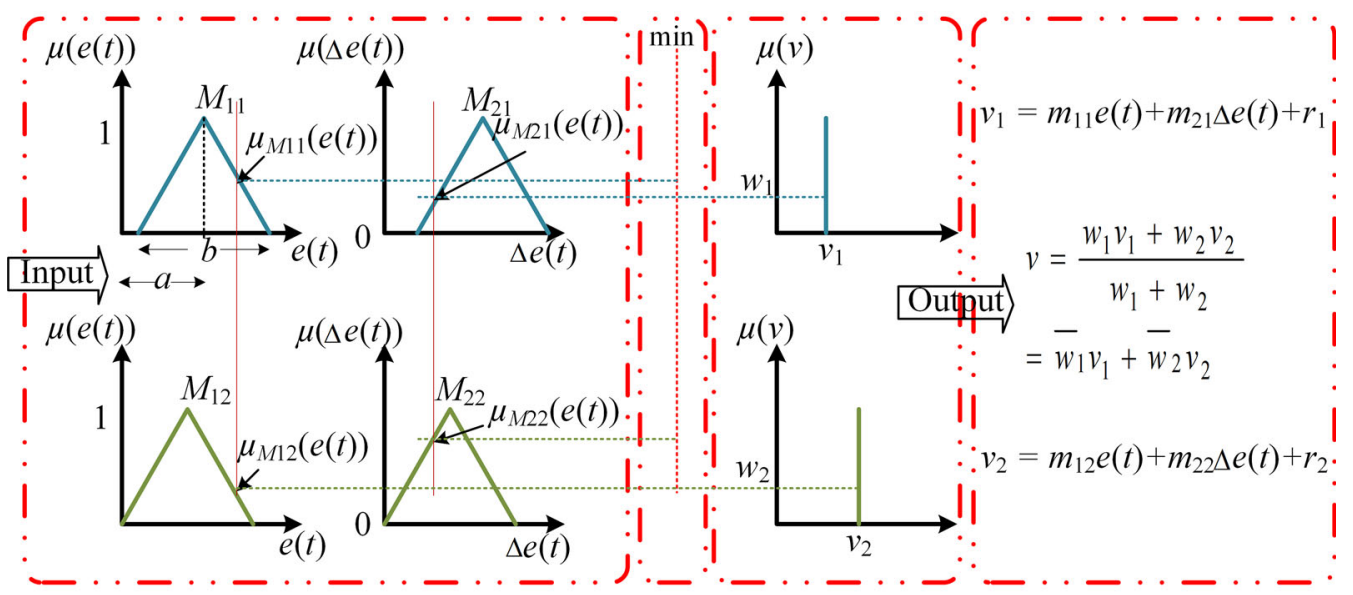

(a)

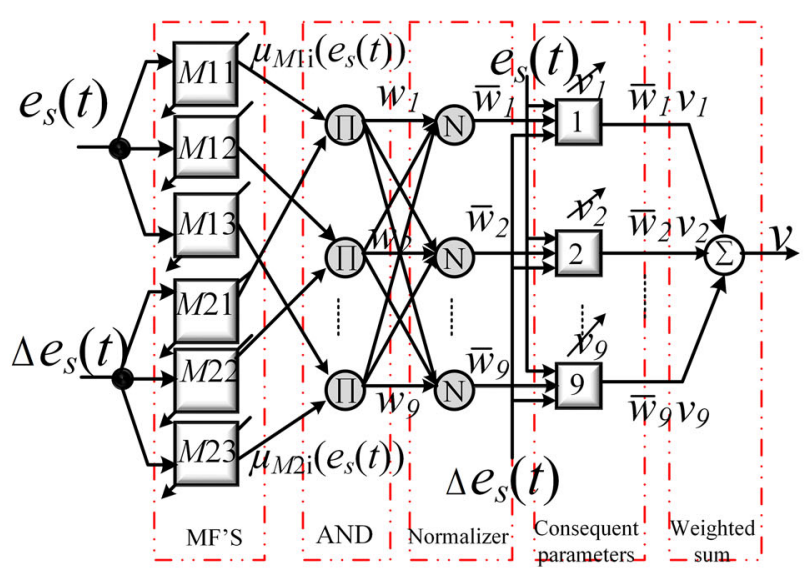

(b)

Figure 4. (a) Sugeno fuzzy model with two rules. (b) Conventional NFC structure with three MFs.

the extra layer introduced here, the minimum error or change in error value of two input weights is picked up as firing strength of rules by the product operator AND, which is symbolized by $\prod$ as shown in figure $4 \mathrm{~b}$ :

$$
\begin{aligned}
O_{i}^{2} & =w_{i}=\mu_{M 1 i}(e(t)) \mu_{M 2 i}(\Delta e(t)) \\
& =\min \left(\mu_{M 1 i}(e(t)), \mu_{M 2 i}(\Delta e(t)), i=1,2,3 .\right.
\end{aligned}
$$

Likewise, the neuro-fuzzy torque controller is designed in the same approach as that of the neuro-fuzzy speed controller. Moreover, the MFs of the neuro-fuzzy torque controller are kept same as those of the neuro-fuzzy speed controller as depicted in figure $3 \mathrm{~b}$, but they have different input and output crisp values as in figure 2 .

Figure 5 shows a surface view of the change in control output of NFC speed and torque controller. The dependence of the output on a single input, error $(E)$, or two inputs, error $(E)$ and change in error (CE), is displayed using the surface viewer. Also, it is defined as the change in control output surface mapping of the system. Figure 6 presents input MFs of proposed and conventional NFC.

\section{Tuning algorithm for proposed NFC}

Instead of employing the desired controller output ' $v$ ' as a target, an error signal ' $e$ ' that evaluates the execution of the controller and calculates the current state of the framework is used to deal with the control action into changing in right directions and also deliver the desired response [41, 42]. A tuning procedure based on backpropagation algorithm is developed here $[22,43,44]$, whose assignment is to upgrade the MFs parameters and weight in order to have minimized error signal, which is considered as a fitness function:

$$
E=\frac{1}{2}\left(\omega_{r}^{*}-\omega_{r}\right)^{2}=\frac{1}{2} e^{2}
$$

where $\omega_{r}^{*}$ is the reference speed and $\omega_{r}$ is the actual or measured speed. To achieve the desired control performance, the backpropagation parameter adaptation rules for instantaneous parameter update are derived as follows: 


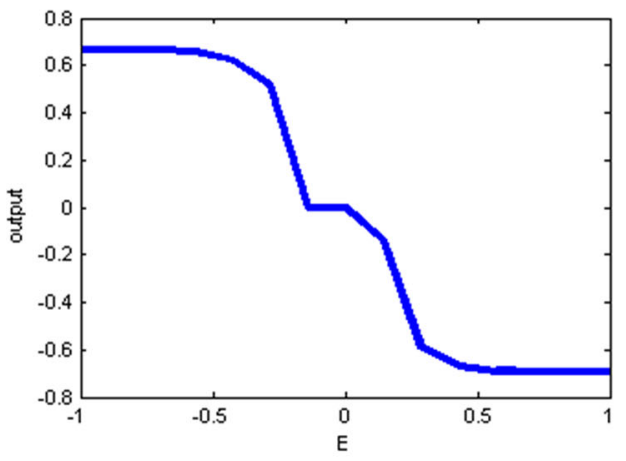

(a)

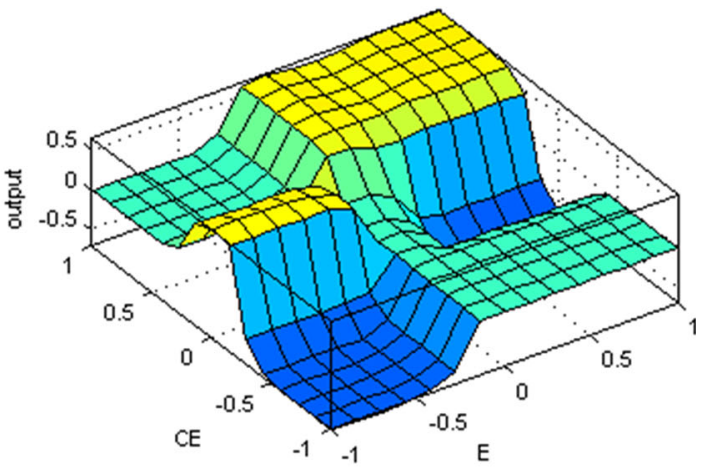

(b)

Figure 5. Surface view of (a) single-input proposed NFC and (b) conventional two-input NFC.

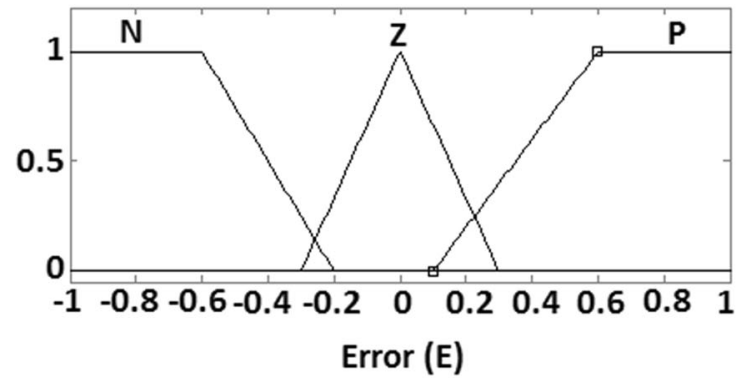

(a)

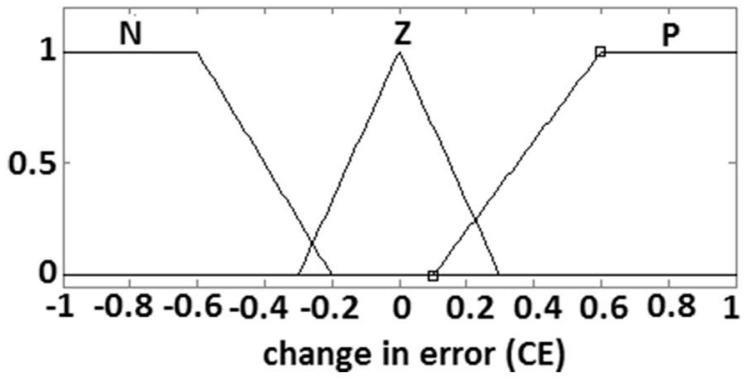

(b)

Figure 6. Input membership functions: error $(E)$ of proposed NFC and error $(E)$ and change in error (CE) of conventional NFC.

$$
\begin{aligned}
a_{i}(k+1) & =a_{i}(k)-\eta_{a i} \nabla_{a i} E(k) \\
b_{i}(k+1) & =b_{i}(k)-\eta_{b i} \nabla_{b i} E(k) \\
w_{i}(k+1) & =w_{i}(k)-\eta_{w i} \nabla_{w i} E(k)
\end{aligned}
$$

where $a_{i}$ and $b_{i}$ are the $i^{\text {th }}$ node values of $a$ and $b, k$ is the sampling instant, $\eta_{a_{i}}, \eta_{b_{i}}, \eta_{w_{i}}$ are the fixed learning rate of parameters $a_{i}, b_{i}, w_{i}$, and $\left(\frac{\partial E}{\partial a_{i}}, \frac{\partial E}{\partial b_{i}}, \frac{\partial E}{\partial w_{i}}\right)$ is denoted as $\left(\nabla_{a_{i}}, \nabla_{b_{i}}, \nabla_{w_{i}}\right)$, which is the gradient of cost function $E$ corresponding to parameters $\left(a_{i}, b_{i}, w_{i}\right)$ and is described by the following equations:

$$
\begin{gathered}
\nabla_{a i} E=\frac{\partial E}{\partial e} \frac{\partial e}{\partial \omega_{r}} \frac{\partial \omega_{r}}{\partial v} \frac{\partial v}{\partial O_{i}^{1}} \frac{\partial O_{i}^{1}}{\partial a_{i}} \\
\nabla_{b i} E=\frac{\partial E}{\partial e} \frac{\partial e}{\partial \omega_{r}} \frac{\partial \omega_{r}}{\partial v} \frac{\partial v}{\partial O_{i}^{1}} \frac{\partial O_{i}^{1}}{\partial b_{i}} \\
\nabla_{w i} E=\frac{\partial E}{\partial e} \frac{\partial e}{\partial \omega_{r}} \frac{\partial \omega_{r}}{\partial v} \frac{\partial v}{\partial w_{i}}
\end{gathered}
$$

The common differential terms of Eqs. (41)-(43) are determined as follows

$$
\begin{gathered}
\frac{\partial E}{\partial e}=\omega_{r}^{*}-\omega_{r}=e \\
\frac{\partial e}{\partial \omega_{r}}=-1 \\
\frac{\partial \omega_{r}}{\partial v}=\text { constant } K
\end{gathered}
$$

The value of $K$ is greater than zero for the proposed IM drive scheme [20,45]. The other terms of Eqs. (41)-(43) are determined from Eqs. (28)-(33) as

$$
\begin{gathered}
\frac{\partial v}{\partial O_{i}^{1}}=\frac{v_{i}(k)}{\sum w_{i}(k)} \\
\frac{\partial O_{i}^{1}}{\partial a_{i}}=\frac{\partial O_{1}^{1}}{\partial a_{1}}=\frac{x_{1}^{1}-b_{1}}{\left(b_{1}-a_{1}\right)^{2}}=-\frac{1-O_{1}^{1}(k)}{b_{1}(k)-a_{1}(k)} \quad \text { for } i=1 \\
\text { Similarly, } \quad \frac{\partial O_{2}^{1}}{\partial a_{2}}=-\frac{1-O_{3}^{1}(k)}{b_{2}(k)-a_{2}(k)} \quad \text { for } i=2
\end{gathered}
$$

$\frac{\partial O_{i}^{1}}{\partial b_{i}}=\frac{\partial O_{1}^{1}}{\partial b_{1}}=-\frac{x_{1}^{1}-a_{1}}{\left(b_{1}-a_{1}\right)^{2}}=-\frac{O_{1}^{1}(k)}{b_{1}(k)-a_{1}(k)} \quad$ for $i=1$ 
Similarly, $\frac{\partial O_{2}^{1}}{\partial b_{2}}=\frac{2\left(x_{2}^{1}-a\right)}{b^{2}}=\frac{1-O_{2}^{1}(k)}{b(k)}$ for $i=2$

$$
\text { and } \begin{gathered}
\frac{\partial O_{3}^{1}}{\partial b_{3}}=-\frac{O_{3}^{1}(k)}{b_{2}(k)-a_{2}(k)} \quad \text { for } i=3 \\
\frac{\partial v}{\partial w_{i}}=\frac{v_{i}(k)}{\sum w_{i}(k)}
\end{gathered}
$$

Substituting Eqs. (47)-(50) in (38)-(40), the following update rules are obtained:

$$
\begin{aligned}
& a_{1}(k+1)=a_{1}(k)-\eta_{a 1} e(k) K \frac{v_{1}(k)}{\sum w_{i}(k)} \frac{1-O_{1}^{1}(k)}{b_{1}(k)-a_{1}(k)} \\
& a_{2}(k+1)=a_{2}(k)-\eta_{a 2} e(k) K \frac{v_{2}(k)}{\sum w_{i}(k)} \frac{1-O_{3}^{1}(k)}{b_{2}(k)-a_{2}(k)} \\
& b_{1}(k+1)=b_{1}(k)-\eta_{b 1} e(k) K \frac{v_{1}(k)}{\sum w_{i}(k)} \frac{O_{1}^{1}(k)}{b_{1}(k)-a_{1}(k)}
\end{aligned}
$$

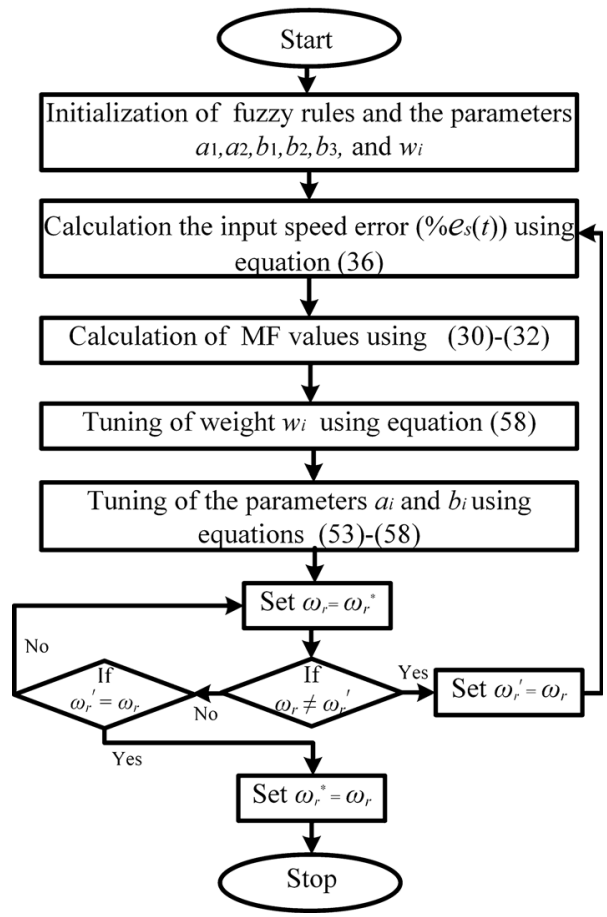

(a)

$$
\begin{gathered}
b_{2}(k+1)=b_{2}(k)+\eta_{b 2} e(k) K \frac{v_{2}(k)}{\sum w_{i}(k)} \frac{1-O_{2}^{1}(k)}{b(k)} \\
b_{3}(k+1)=b_{3}(k)-\eta_{b 3} e(k) K \frac{v_{3}(k)}{\sum w_{i}(k)} \frac{O_{3}^{1}(k)}{b_{2}(k)-a_{2}(k)} \\
w_{i}(k+1)=w_{i}(k)+\eta_{w i} e(k) K \frac{v_{i}(k)}{\sum w_{i}(k)} .
\end{gathered}
$$

The step-wise procedure followed for parameter tuning using the update rules given by Eqs. (51)-(56) is shown in figure $7 \mathrm{a}$. Similarly, the same auto-tuning method is performed to update the proposed simplified neuro-fuzzy-torque control, where the error signal is defined as

$$
E=\frac{1}{2}\left(T_{e}^{*}-T_{e}\right)^{2}=\frac{1}{2} e^{2}
$$

where $T_{e}^{*}$ is the reference torque, which is the output of the neuro-fuzzy speed controller, and $T_{e}$ is the actual or estimated torque.

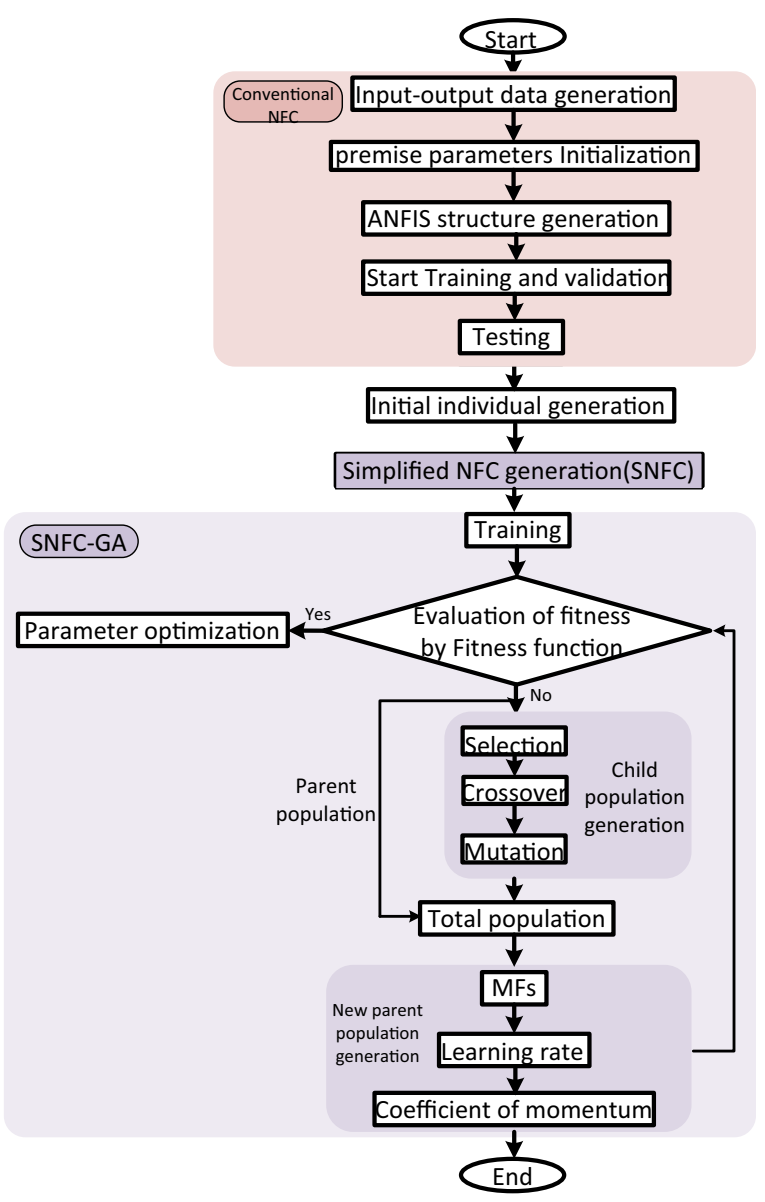

(b)

Figure 7. Flowchart for (a) tuning of the parameters to optimize the error signal and (b) modelling steps of applied methods using GA. 


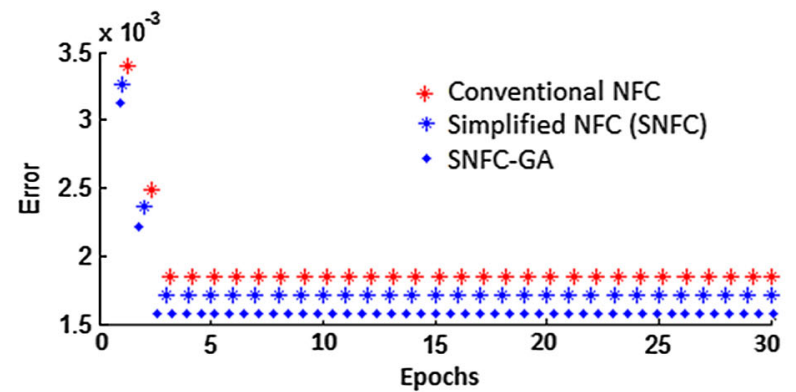

(a)

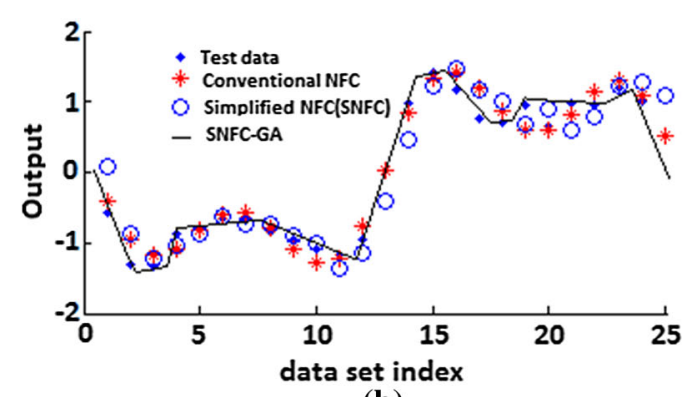

(b)

Figure 8. Comparison of (a) training error for different controllers and (b) testing data sets for different controllers.

Some parameters of the SNFC are still unoptimized due to the neural network (NN) as it tries to find out the optimal parameters of the fuzzy logic control and during the process, it may be confined in local minima instead of global minima. This causes an impact on the performance of the drive system indirectly. Hence, to confront this issue, a powerful optimization method GA is integrated with the proposed SNFC to optimize MFs, learning rate of NN and coefficient of momentum [46]. The modelling algorithm of SNFC with GA (SNFC-GA) is demonstrated in figure 7b. The performance assessment of the linearized IM drive is also done by comparing SNFC-GA-based drive. Since GA controls the training step and picks up the optimized parameters at every iteration, it is not required to rectify the NFC model.

The testing data set generated for conventional NFC, SNFC and SNFC-GA is shown in figure $8 b$, which shows that the SNFC-GA gives the best fit with the test data (actual data). Therefore, the mean square error of the SNFC-GA is found to be the least, with value 0.00158 , as shown in figure 8a. The training was based on 30 iterations; however, prior to five iterations, the controllers settled down to the minimum error of $0.00187,0.00175$ and 0.00158 for conventional NFC, SNFC and SNFC-GA, respectively. By testing different values for the parameters, i.e., mutation rate, learning rate and coefficient of momentum, the GA makes the structure the best with faster convergence. The optimized parameters using SNFC-GA are illustrated in the Appendix.

\section{Experimental set-up}

The proposed auto-tuned NFC-based control of feedbacklinearized IM drive system was validated in real time using the platform of 32-bit fixed point DSP TMS320F2812. The prototype real-time and experimental set-ups are illustrated in figure $9 \mathrm{a}$ and $\mathrm{b}$, respectively. The motor specifications are the same as given in the Appendix. Hall-effect voltage sensor and current sensor (LEM LTS 25-NP) sense the actual motor line voltages and currents, respectively, which are fed to the DSP board through A/D channel. The rotor speed is sensed by the speed encoder. The hysteresis-current-controlled PWM signals are generated by the DSP board, which are fed to the switches of the three-phase voltage source inverter. To get the load perturbation for torque analysis, IM is coupled to a DC motor shaft. Then, by introducing resistance on its armature circuit, load torque is varied. Other than current, all the variables of this

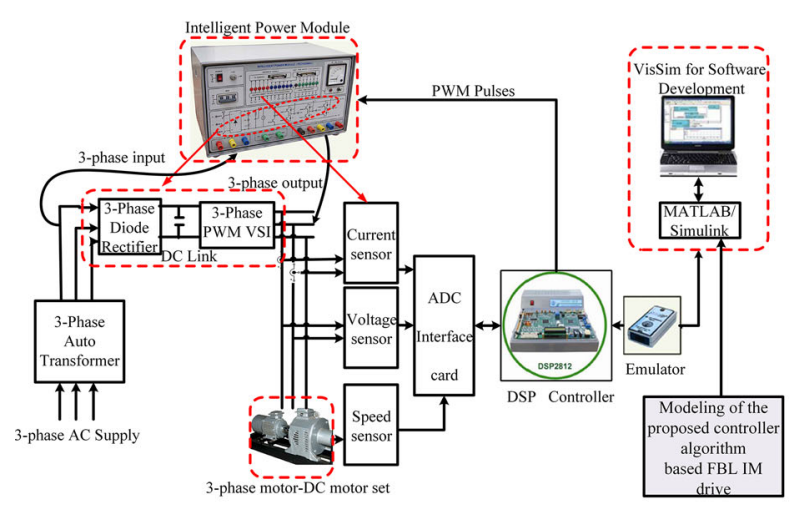

(a)

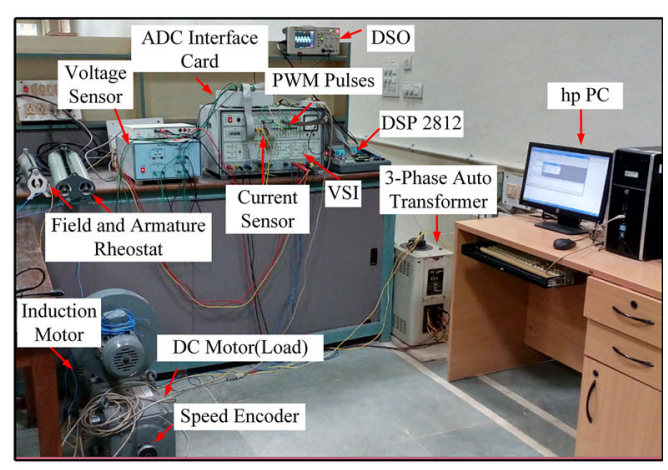

(b)

Figure 9. (a) Block diagram for prototype real-time set-up and (b) experimental set-up. 


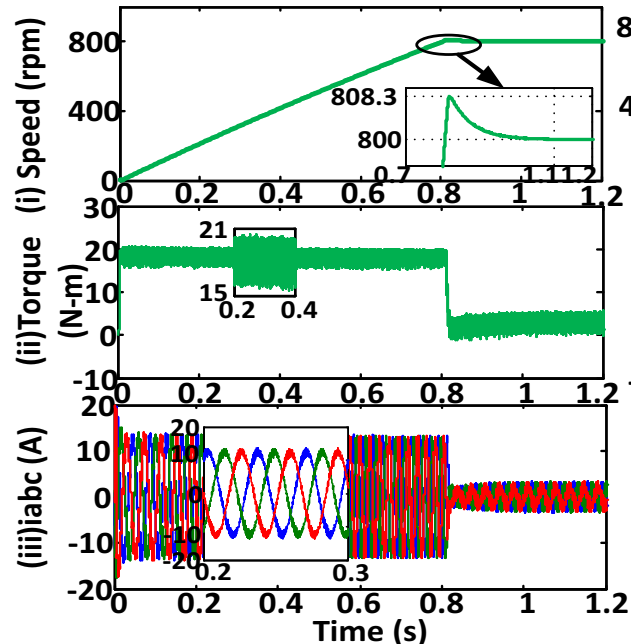

(a)

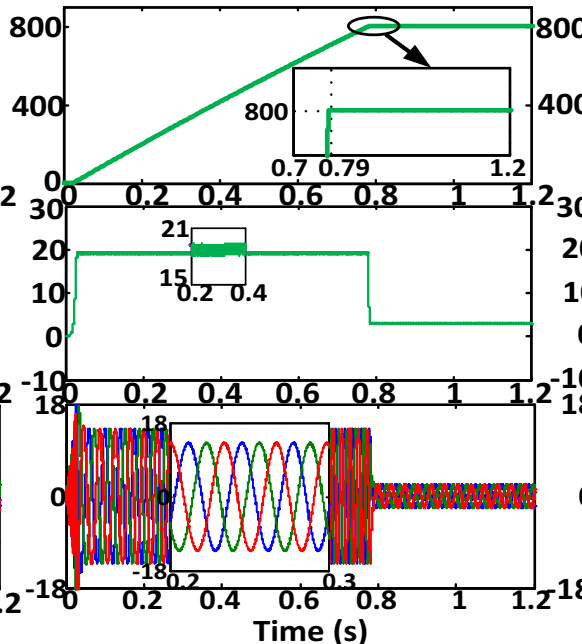

(b)

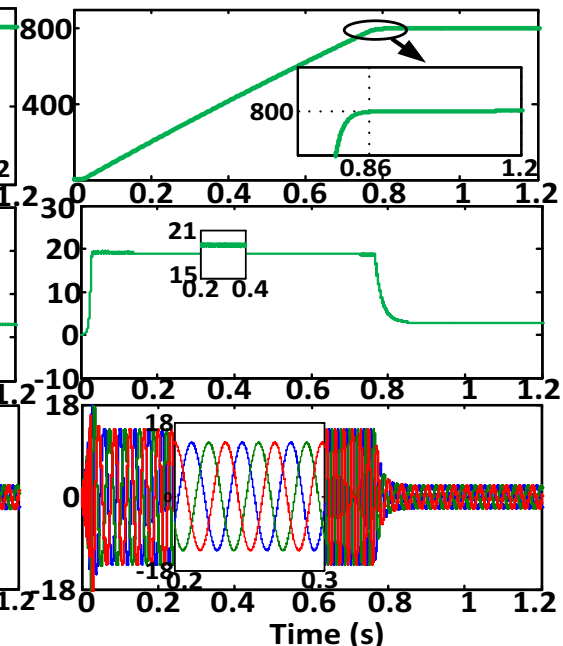

(c)

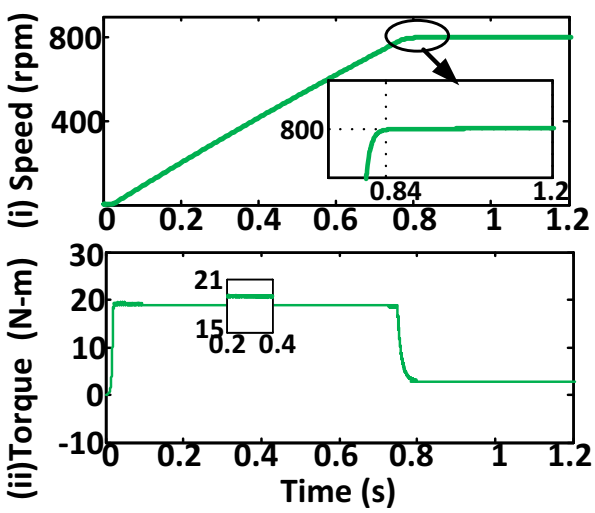

(d)

Figure 10. Start-up response of feedback-linearization-controlled IM drive using (a) PI controller: (i) speed ( $\left.n_{r}\right)$, (ii) torque (Te) and (iii) stator current $(i a b c)$; (b) conventional NFC: (i) $n_{r}$, (ii) $T e$ and (iii) $i a b c$; (c) proposed SNFC: (i) $n_{r}$, (ii) $T e$ and (iii) $i a b c$ and (d) proposed NFC with GA: (i) $n_{r}$ and (ii) $T e$.

test are observed through a D-A converter and are displayed on a digital oscilloscope.

The developed real-time Simulink model of proposed NFC with the auto-tuning algorithm is compiled and transferred to the DSP board using an emulator as in figure $9 \mathrm{a}$. However, the tuning rate of the weight $\eta_{w i}$ and the tuning rate of the MFs $\left(\eta_{a i}, \eta_{b i}\right)$ given in the Appendix are chosen to be very small by trial and error as it smoothens the transition. A conventional two-input NFC and PI-controller-based linearized drive system are also validated experimentally in order to have a fair comparison. As the structure of the proposed NFC is simplified, to conduct this operation, the lowest sampling time required is $100 \mu \mathrm{s}$ whereas it is $250 \mu$ s for conventional NFC. The PI speed and torque controller tuning was done by trial and error method with regard to zero steady-state error, settling time, speed overshoot and undershoot of the response so that it gives a fair comparison with that of the NFCs. It is possible to make the PI controller [47] as critically damped, but it gave extremely sluggish response, which cannot be even comparable with the proposed NFC-based drive scheme. Thus, $K_{p}$ and $K_{i}$ are considered to be 20 and 0.02 , respectively, for PI-speed controller, and 10 and 0.01 for PI-torque controller, respectively.

\section{Results and analysis}

\subsection{Simulation results}

The effectiveness of proposed modified NFC-based control of linearized IM drive is investigated by MATLAB/Simulink using a hysteresis-current-controlled PWM inverter with the same sampling time as that of experiment for 3.7 kW IM under various modes of operations. Figures 10-14 present comparison of responses of the proposed NFCbased drive with conventional NFC and PI-controller-based drive under different working modes. It is witnessed that the results of proposed SNFC-based drive are found to be similar to those of conventional NFC and, simultaneously, 
Table 1. Simulated comparative analysis using different controllers.

\begin{tabular}{|c|c|c|c|c|c|c|c|c|c|c|c|}
\hline \multirow[b]{3}{*}{ Controller } & \multicolumn{9}{|c|}{ Modes of operations of IM } & \multirow{3}{*}{$\begin{array}{c}\text { Integral } \\
\text { time } \\
\text { absolute } \\
\text { error } \\
\text { (ITAE) } \\
\text { under } \\
\text { load }\end{array}$} & \multirow[b]{3}{*}{$\begin{array}{c}\text { Mean } \\
\text { square } \\
\text { error } \\
\text { (MSE) }\end{array}$} \\
\hline & \multicolumn{3}{|c|}{ Starting } & \multicolumn{3}{|c|}{ Loading } & \multicolumn{3}{|c|}{ Reversing } & & \\
\hline & $\begin{array}{l}\text { Torque } \\
\text { ripple } \\
(\mathrm{Nm})\end{array}$ & $\begin{array}{l}\text { Speed } \\
\text { ripple } \\
(\mathrm{rpm})\end{array}$ & $\begin{array}{c}\text { Speed } \\
\text { overshoot } \\
(\%)(\mathrm{rpm})\end{array}$ & $\begin{array}{l}\text { Torque } \\
\text { ripple } \\
(\mathrm{Nm})\end{array}$ & $\begin{array}{l}\text { Speed } \\
\text { ripple } \\
(\mathrm{rpm})\end{array}$ & $\begin{array}{l}\text { Speed } \\
\text { undershoot/ } \\
\text { overshoot } \\
(\%)(\mathrm{rpm})\end{array}$ & $\begin{array}{c}\text { Torque } \\
\text { ripple } \\
(\mathrm{Nm})\end{array}$ & $\begin{array}{l}\text { Speed } \\
\text { ripple } \\
(\mathrm{rpm})\end{array}$ & $\begin{array}{c}\text { Speed } \\
\text { undershoot } \\
(\%)(\mathrm{rpm})\end{array}$ & & \\
\hline PI controller & 4.5 & 0.1 & 8.3 & 4.5 & 0.1 & 1.7 & 4.5 & 0.06 & 9 & 1.7 & - \\
\hline $\begin{array}{l}\text { Conventional } \\
\text { NFC }\end{array}$ & 0.5 & 0.005 & 0 & 0.5 & 0.005 & 1.4 & 0.5 & 0.005 & 0 & 0.5 & 0.00187 \\
\hline $\begin{array}{l}\text { Proposed } \\
\text { NFC }\end{array}$ & 0.3 & 0.003 & 0 & 0.3 & 0.003 & 1.4 & 0.3 & 0.003 & 0 & 0.38 & 0.00175 \\
\hline $\begin{array}{l}\text { Proposed } \\
\text { NFC with } \\
\text { GA }\end{array}$ & 0.25 & 0.003 & 0 & 0.25 & 0.003 & 1.4 & 0.25 & 0.003 & 0 & 0.35 & 0.00158 \\
\hline
\end{tabular}

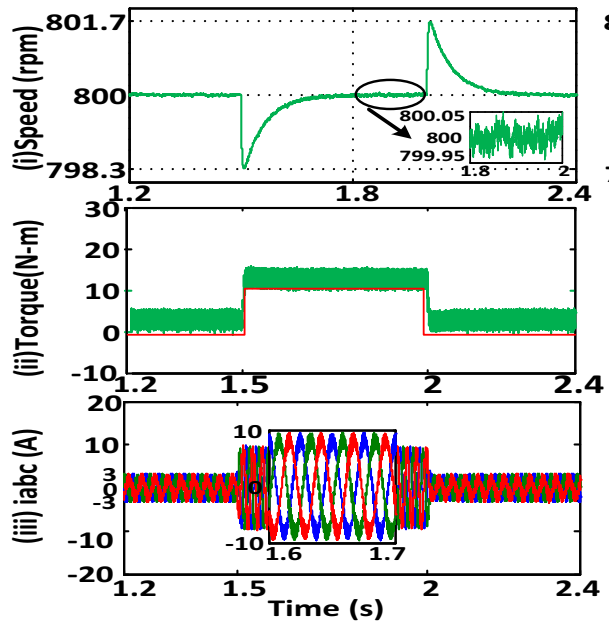

(a)

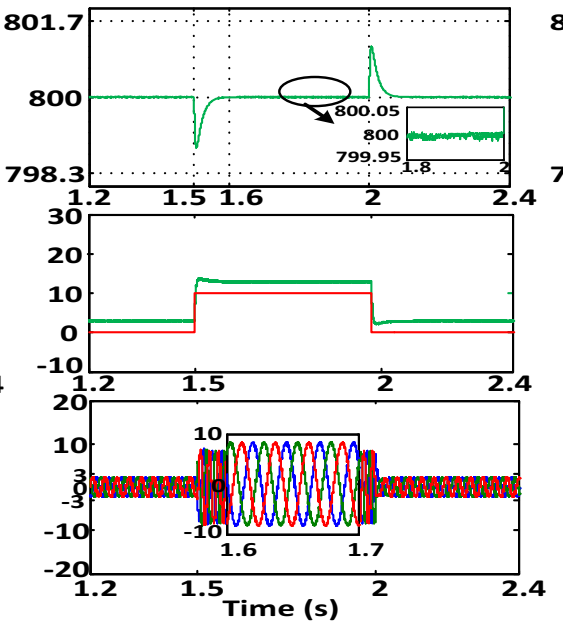

(b)

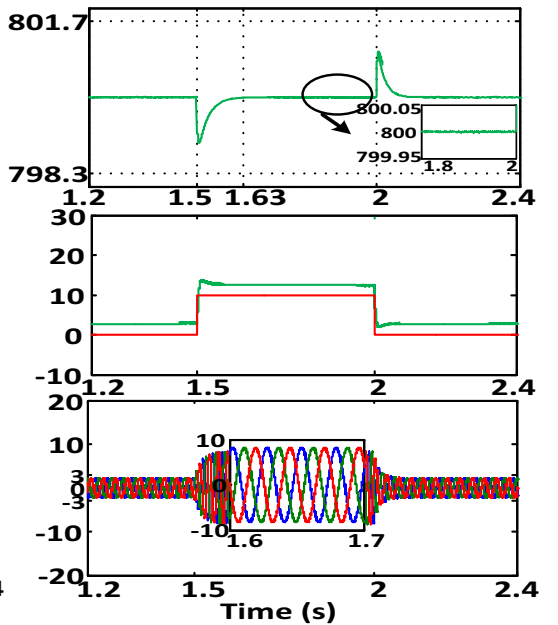

(c)

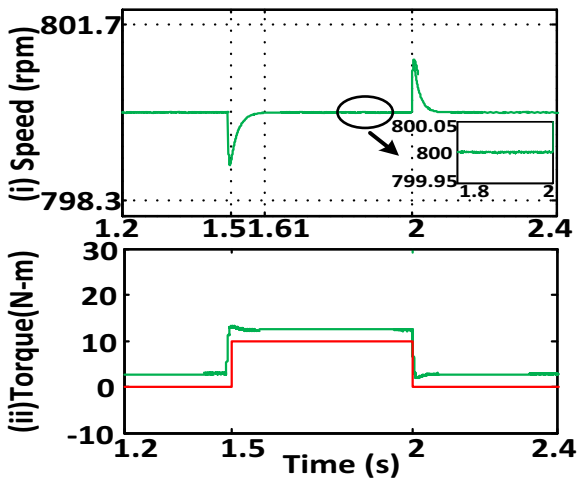

(d)

Figure 11. Load characteristics of feedback-linearization-controlled (FBL) IM drive during 50\% step change in load from 1.5 to $2 \mathrm{~s}$ using (a) PI controller: (i) speed $n_{r}$, (ii) torque $T e$ and (iii) stator current $i a b c$; (b) conventional NFC: (i) $n_{r}$, (ii) $T e$ and (iii) $i a b c$; (c) proposed NFC: (i) $n_{r}$, (ii) $T e$ and (iii) $i a b c$ and (d) proposed NFC with GA: (i) $n_{r}$ and (ii) $T e$. 
enhanced performance than that of conventional PI controller is observed, which is evident from table 1. IM specifications are illustrated in the Appendix.

6.1a Results with PI controller Case 1: This illustrates that the motor accelerates at a constant rate and reaches its set point speed of $800 \mathrm{rpm}$ in $1.1 \mathrm{~s}$ with an overshoot and applied DC-link voltage of $646 \mathrm{~V}$ as shown in figure 10a(i) and figure 13a(iii). The current, torque and speed of IM are settled at $1.1 \mathrm{~s}$. However, the spike in capacitor voltage $\mathrm{Vc}$ is observed initially as the capacitor charges and settles down later within 5-6 cycles by discharging through a properly selected switching path as in figure 13a(iii). Substantial ripple and chattering in torque and speed appear with this PI controller.

Case 2: The dynamics of load disturbance is studied by a step increase in load from $0 \%$ to $50 \%$ from 1.5 to $2 \mathrm{~s}$ when the motor operates at steady-state speed of $800 \mathrm{rpm}$ and is depicted in figure 11. It leads to undershoot and overshoot in the speed of about $1.7 \mathrm{rpm}$ at 1.5 and $2 \mathrm{~s}$, respectively, with settling period of around 14-15 cycles (0.3 s), accompanied by an increase in stator current to $10 \mathrm{~A}$. Also, the capacitor voltage is reduced to $644 \mathrm{~V}$ during the sudden increase of stator current at $1.5 \mathrm{~s}$ as the energy stored in the capacitor gets released when the large current is drawn by motor through the capacitor and comes to the steady state after one cycle $(0.02 \mathrm{~s})$. Likewise, the capacitor starts discharging and charging during application and removal of the load, which is evident from figure 13a(iii). With this PI controller, extensive ripples in torque and speed are evident from figure 11a.

Case 3: Subsequently, speed reversal takes place at $2.5 \mathrm{~s}$, at a uniform rate to zero speed and then to $-400 \mathrm{rpm}$ at $3.8 \mathrm{~s}$ as shown in figure 12a. This is accompanied by large stator current due to large negative motor torque; during reversing, the frequency of the current reduces, first due to the controller using regenerative braking, followed by phase reversal for getting the motor reversed. Further, it is evident from figure 12 that the responses replicate those of the start-up operation as shown in figure 10. Detailed analysis of comparative performance is illustrated in table 1. However, all through these three operations, the flux is maintained uniform as evident from figure 13a(ii).

\subsection{Results with NFC}

Operating conditions similar to those of the PI controller were carried out for starting, loading and speed reversing as shown in figures 10-14. Initially, the stator current is less (18 A) with less distortion, reduced settling time, less peak capacitor voltage $\mathrm{Vc}$ and reduced torque ripple using proposed and conventional NFC-based linearized drive over PI-controller-based drive. The torque response during starting is significantly improved as the torque ripple is remarkably reduced. It is evident from table 1 that the low computational proposed SNFC bears a resemblance to that of conventional NFC and, simultaneously, it shows better performance over the traditional PI-controller-based drive with respect to ripple, rise time, settling time and overshoot. Further, it is observed from figure 10d that the proposed NFC with GA-based drive does have very little impact on performance in terms of ripple and settling time $(0.84 \mathrm{~s})$ as compared to the proposed NFC-based drive only. During load perturbation at the same instant of PI-controller-based

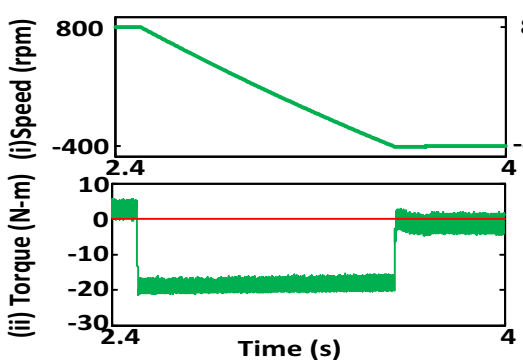

(a)

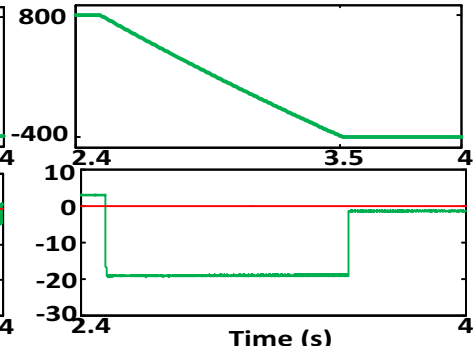

(b)

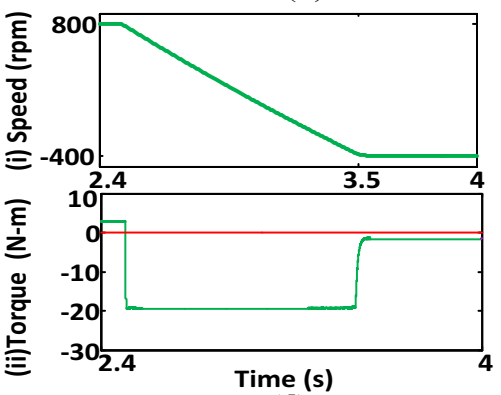

(d)

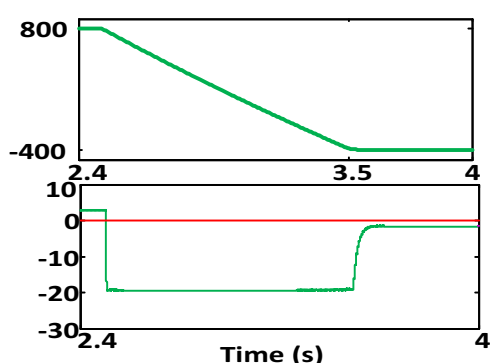

(c)

Figure 12. Speed reversal characteristics of FBL-controlled IM drive using (a) PI controller: (i) speed $n_{r}$ and (ii) torque Te; (b) conventional NFC: (i) $n_{r}$ and (ii) $T e$; (c) proposed NFC: (i) $n_{r}$ and (ii) $T e$ and (d) proposed NFC with GA: (i) $n_{r}$ and (ii) $T e$. 


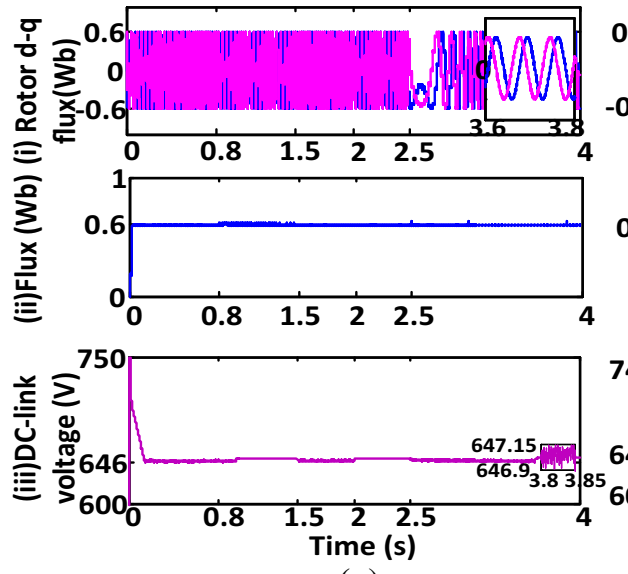

(a)
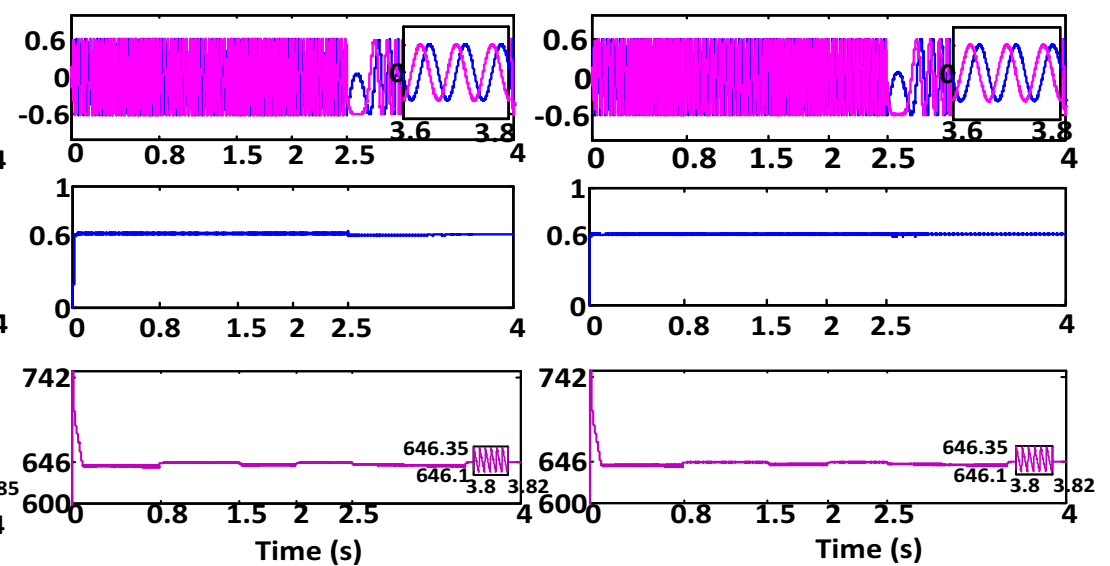

(b)

(c)

Figure 13. Simulated characteristics (starting, 50\% loading from 1.5 to $2 \mathrm{~s}$ and reversal) of FBL-controlled IM drive by (a) PI controller: (i) rotor $d-q$ flux, (ii) flux and (iii) DC-link voltage $V c$; (b) conventional NFC: (i) rotor $d-q$ flux, (ii) flux and (iii) DC-link voltage $V c$ and (c) proposed NFC: (i) rotor $d-q$ flux, (ii) flux and (iii) DC-link voltage $V c$.
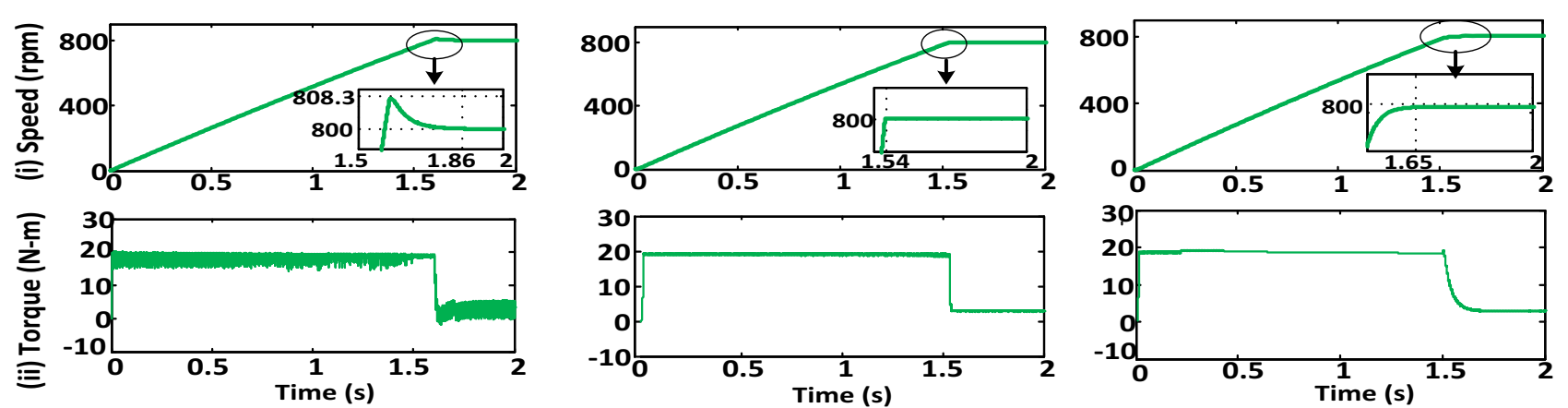

(a)

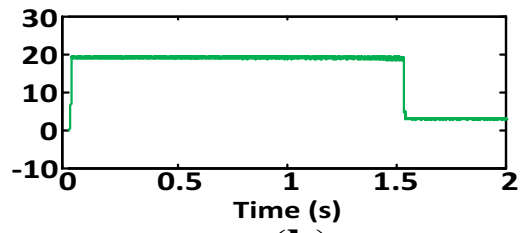

(b)

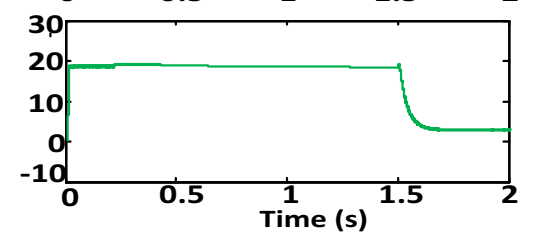

(c)

Figure 14. Start-up behaviour of FBL-based IM drive with doubled rotor inertia by (a) PI controller: (i) speed $n_{r}$ and (ii) torque Te; (b) conventional NFC: (i) $n_{r}$ and (ii) $T e$ and (c) proposed NFC: (i) $n_{r}$ and (ii) $T e$.

linearized IM, it is seen that the implementation of the proposed NFC and NFC-GA enhances the speed tracking performance with significantly less ripple, less fluctuation and less settling time of around 5-6 cycles, which are superior to those of the PI controller. The torque ripples with the proposed NFC are extensively reduced compared PI controller, thereby decreasing the magnitude and distortion of the motor current, as evident from figure 11(iii). There is a slight reduction of torque ripple and settling time using SNFC-GA-based drive over the proposed NFC as shown in figure 11d and the details are illustrated in table 1 . In fact, the oscillation in speed has almost disappeared by the proposed NFC and NFC-GA-based drive as compared with the conventional NFC, which still has a tiny oscillation, as in figure 11c(i). Subsequently, while reversing the speed, the motor settles down faster at $3.6 \mathrm{~s}$ for proposed NFC and NFC-GA-based drive as compared with PI-controller-based drive. The torque response and settling time of the proposed NFC-GA-based drive are improved as compared with the proposed NFC-based drive only as shown in figure $12 \mathrm{~d}$. Detailed analysis of the proposed SNFC with the GA-based drive is depicted in table 1 . Moreover, the linearized IM with this controller has less dip in capacitor voltage and less flux and torque distortion. Also, figure 13 reveals that the rotor flux is steady throughout every operating mode regardless of the speed and the proposed low computational NFC establishes the perfect decoupling without compromising on the system behaviour. Additionally, it exhibits superior performance as compared with the classical PI controller.

The robustness of the proposed NFC-based FBL controller in face of the motor parameter detuning is examined with the doubled rotor inertia as shown in figure 14. The settling time response is almost doubled as the rotor inertia is doubled. The responses demonstrate the robustness stability of proposed NFC as compared with PI-controllerbased drive.

Since the IM has highly nonlinear dynamics, the issue of power quality is the major challenge in real practice, which is another aspect of the research area of IM drive. However, 


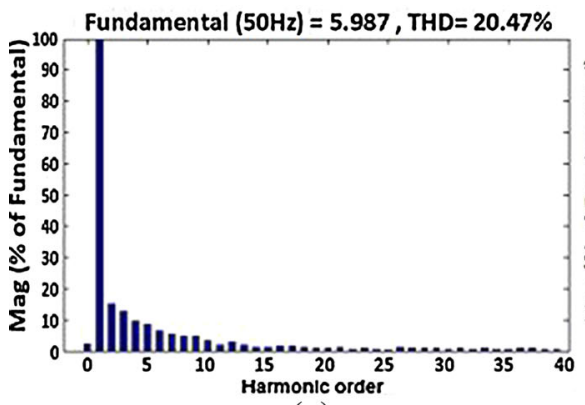

(a)

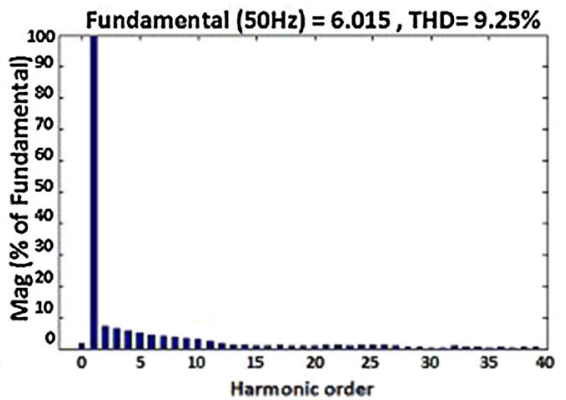

(b)

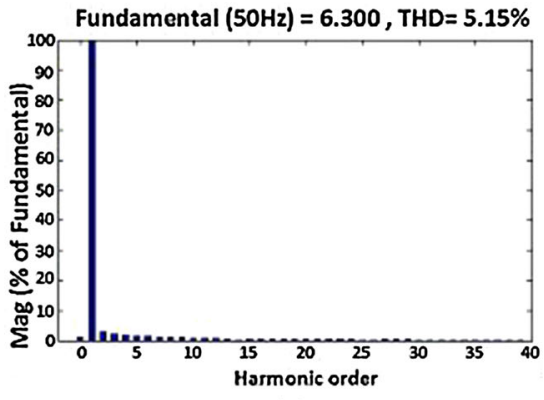

(c)

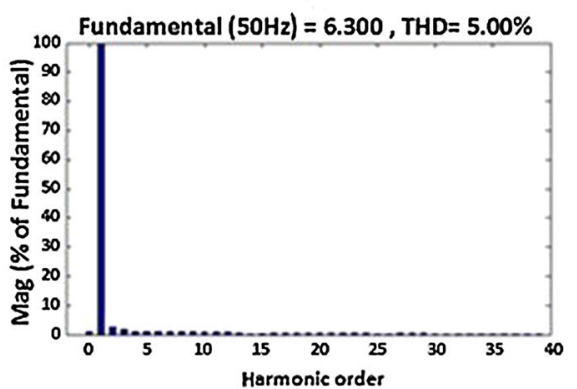

(d)

Figure 15. The THD performance of linearized induction motor drive for current harmonics under $50 \%$ of the 10 ad (10 Nm): (a) PI controller, (b) conventional two-input NFC, (c) proposed NFC and (d) proposed NFC with GA.

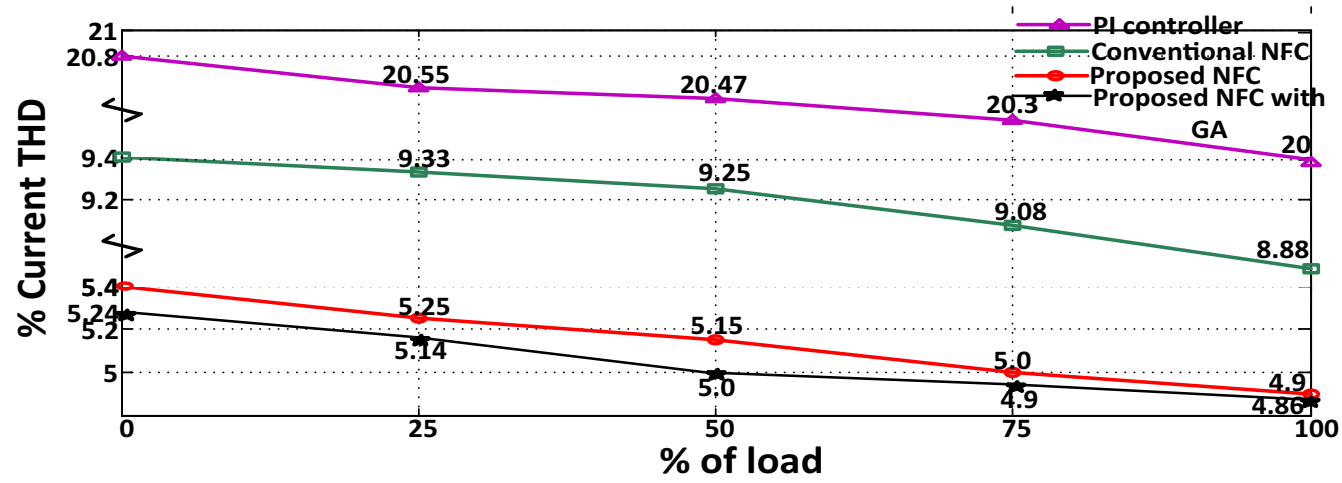

Figure 16. Comparative \% THD vs. load performance of feedback-linearized IM for different controllers.

in the proposed NFC-based drive, the power quality in terms of total harmonic distortion (THD) for supply current harmonics with load of $10 \mathrm{Nm}$ is found to be $5.15 \%$, which is lower as compared with conventional NFC and PI-controller-based drive having THD of $9.25 \%$ and $20.47 \%$, respectively. This indicates that the power quality in case of the proposed drive is improved as the current harmonic is drastically lesser than that of the PI-controller-based drive. These results are evident from figure 15. The reason for less THD in the NFC-based drive is because of the optimum selection of rules by learning method of ANN. However, the proposed NFC with GA-based drive has comparatively less THD (5\%) as in figure $15 \mathrm{~d}$ with respect to the proposed SNFC-based drive. This is because of the optimal parameter selection due to $\mathrm{GA}$ along with the optimized rules obtained by NFC. Also, the NFC-based drive has the significant advantage of controlling pulse signal, which is independent of sampling time. This leads to improved firing strength of the inverter and better power quality of IM drive. Figure 16 presents the current THD vs. load for different controllers of linearized IM drive. The current THD gets reduced as the load increases from noload to full-load.

\subsection{Experimental validation}

The efficacy of the proposed NFC-based drive is verified and compared in the real-time analysis under different 


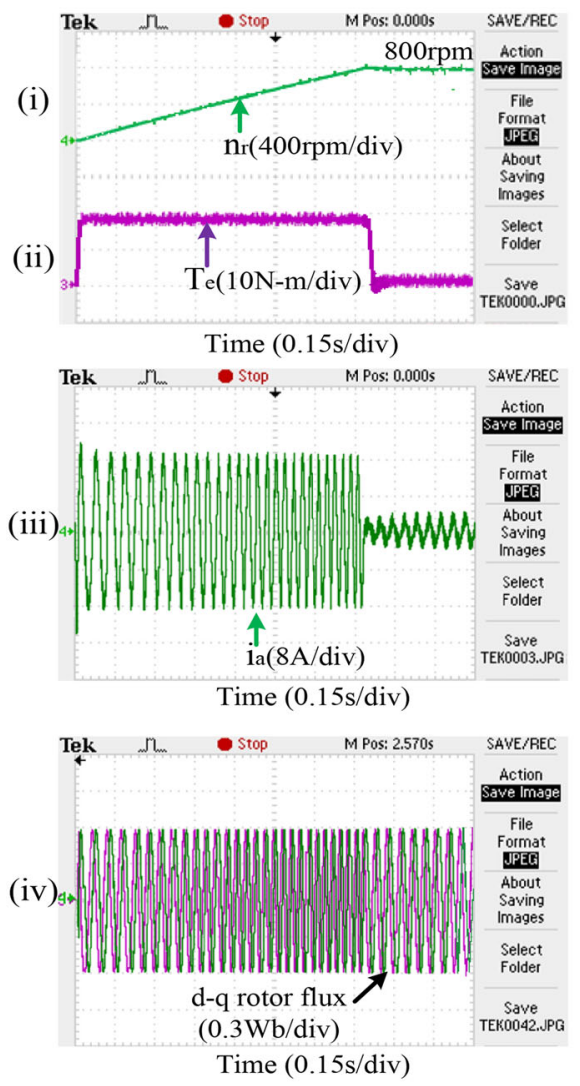

(a)
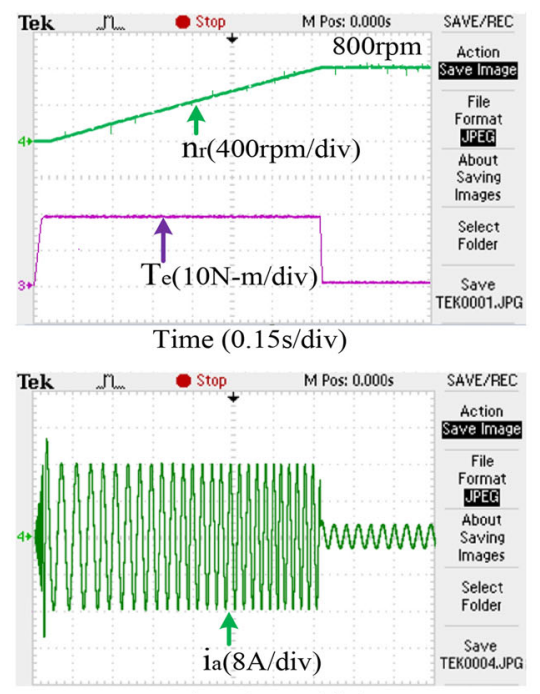

Time $(0.15 \mathrm{~s} / \mathrm{div})$

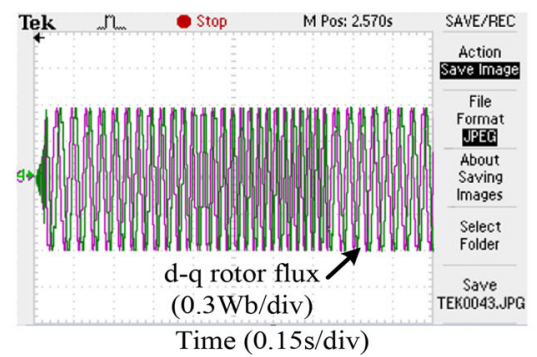

(b)
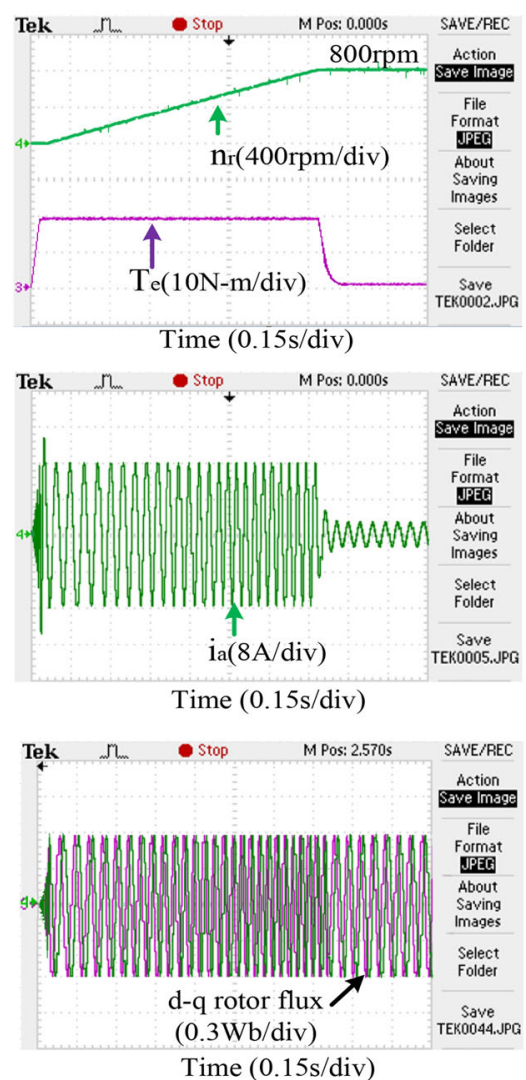

(c)

Figure 17. The experimental no-load starting responses of FBL-controlled motor drive for $800 \mathrm{rpm}$ using (a) PI controller: (i) speed $n_{r}$, (ii) torque $T e$, (iii) stator current $i_{a}$ and (iv) rotor $d-q$ flux $\Psi_{d q r}$; (b) conventional NFC: (i) $n_{r}$, (ii) $T e$, (iii) $i_{a}$ and (iv) $\Psi_{d q r}$ and (c) proposed simplified NFC: (i) $n_{r}$, (ii) $T e$, (iii) $i_{a}$ and (iv) $\Psi_{d q r}$.

Table 2. Controllers' simulated and experimental performance analysis.

\begin{tabular}{|c|c|c|c|c|c|c|c|}
\hline \multirow[b]{4}{*}{ Controller } & \multirow{2}{*}{\multicolumn{2}{|c|}{ Speed $(\mathrm{rpm})$}} & \multirow{2}{*}{\multicolumn{2}{|c|}{ Torque ripples $(\mathrm{Nm})$}} & \multicolumn{3}{|c|}{ Settling time (s) } \\
\hline & & & & & \multirow[b]{3}{*}{ Different time instants (s) } & \multirow{3}{*}{$\begin{array}{c}\text { Simulation } \\
t_{s}\left(n_{r}\right)\end{array}$} & \multirow{3}{*}{$\begin{array}{c}\text { Experimen } \\
t_{s}\left(n_{r}\right)\end{array}$} \\
\hline & \multicolumn{2}{|c|}{$\begin{array}{l}\text { Undershoot and overshoot } \\
\text { during } 50 \% \text { of rated load }\end{array}$} & \multirow[b]{2}{*}{ Simulation } & \multirow[b]{2}{*}{ Experiment } & & & \\
\hline & Simulation & Experiment & & & & & \\
\hline \multirow[t]{4}{*}{ PI controller } & 1.7 & 2.16 & 4.5 & 5 & 0 & 1.1 & 1.38 \\
\hline & & & & & 1.5 & 1.8 & 1.84 \\
\hline & & & & & 2 & 2.3 & 2.34 \\
\hline & & & & & 2.5 & 3.8 & 3.85 \\
\hline \multirow[t]{4}{*}{ Conventional NFC } & 1.4 & 1.44 & 0.5 & 0.7 & 0 & 0.79 & 1.08 \\
\hline & & & & & 1.5 & 1.6 & 1.62 \\
\hline & & & & & 2 & 2.1 & 2.12 \\
\hline & & & & & 2.5 & 3.51 & 3.55 \\
\hline \multirow[t]{4}{*}{ Proposed NFC } & 1.4 & 1.44 & 0.3 & 0.5 & 0 & 0.86 & 1.15 \\
\hline & & & & & 1.5 & 1.63 & 1.66 \\
\hline & & & & & 2 & 2.13 & 2.16 \\
\hline & & & & & 2.5 & 3.6 & 3.64 \\
\hline
\end{tabular}


(i)

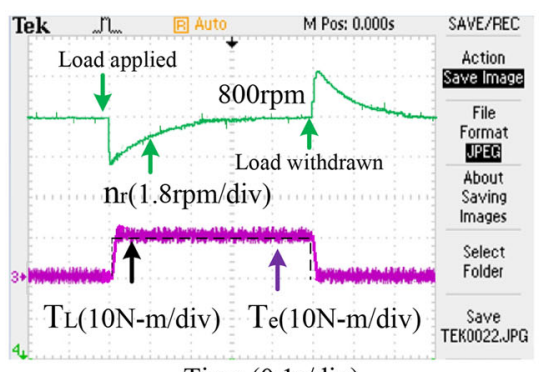

(ii)

(iii)

(iv)

(v)
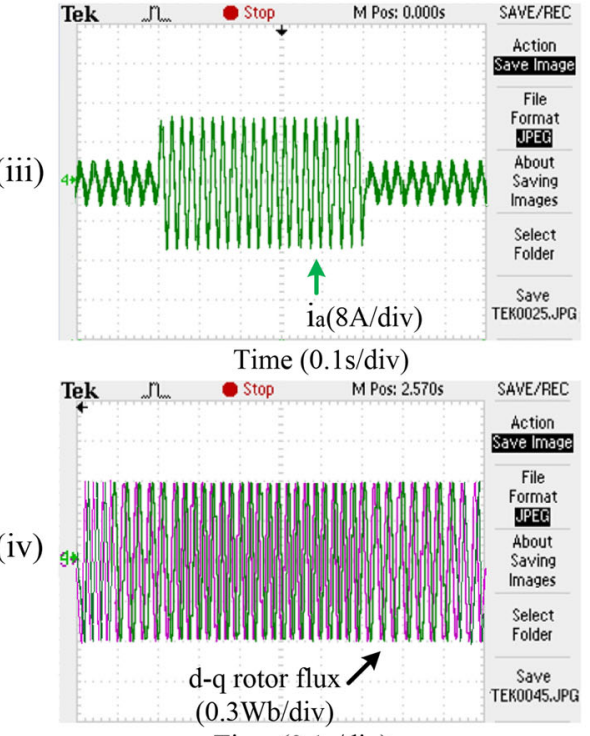

Time $(0.1 \mathrm{~s} /$ div $)$

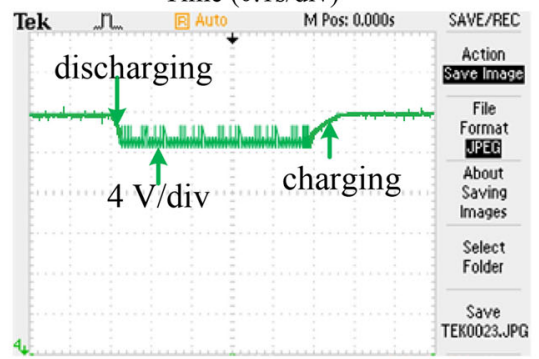

Time $0.1 \mathrm{~s} / \mathrm{div}$

(a)
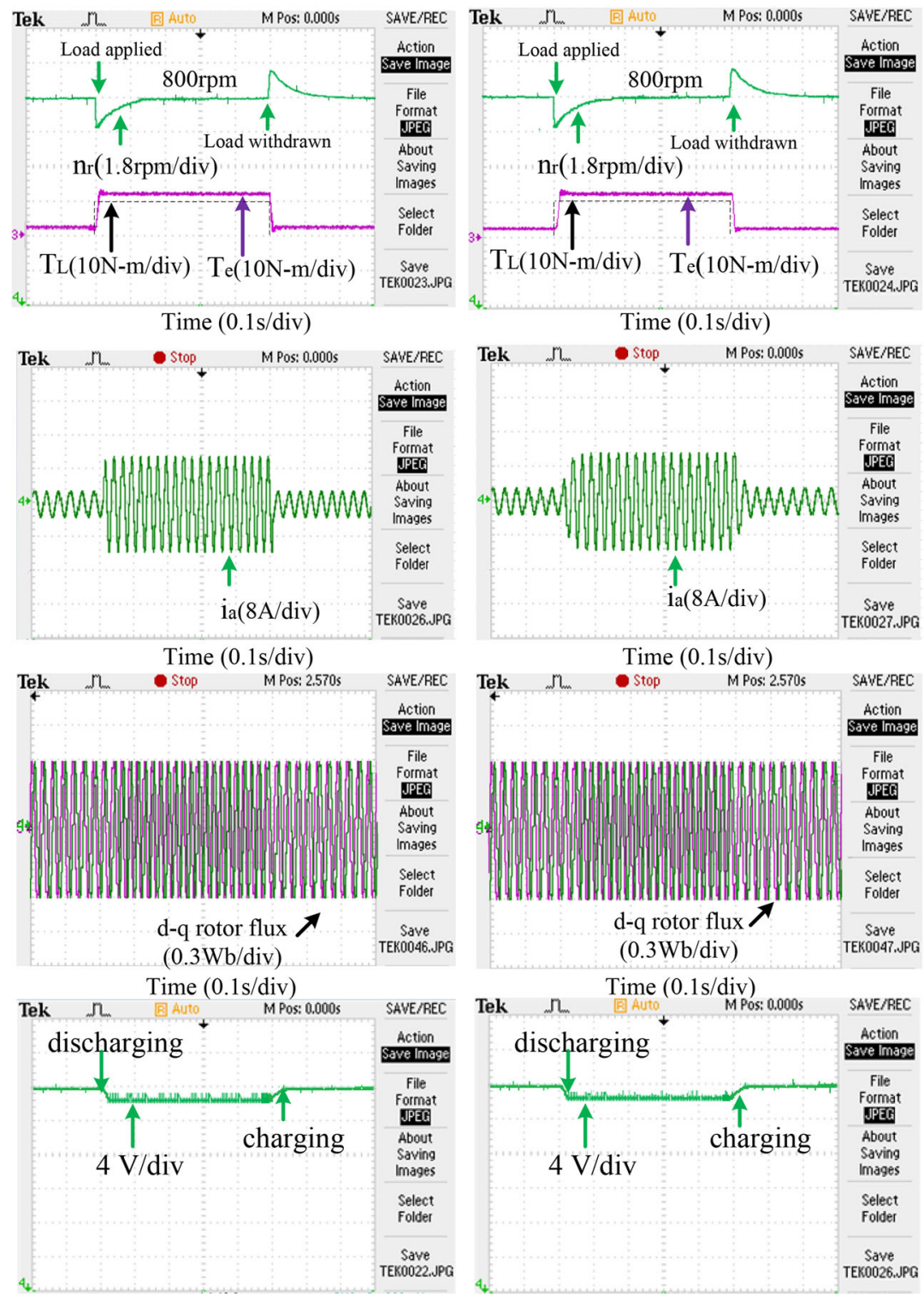

Time $0.1 \mathrm{~s} / \mathrm{div}$

(b)

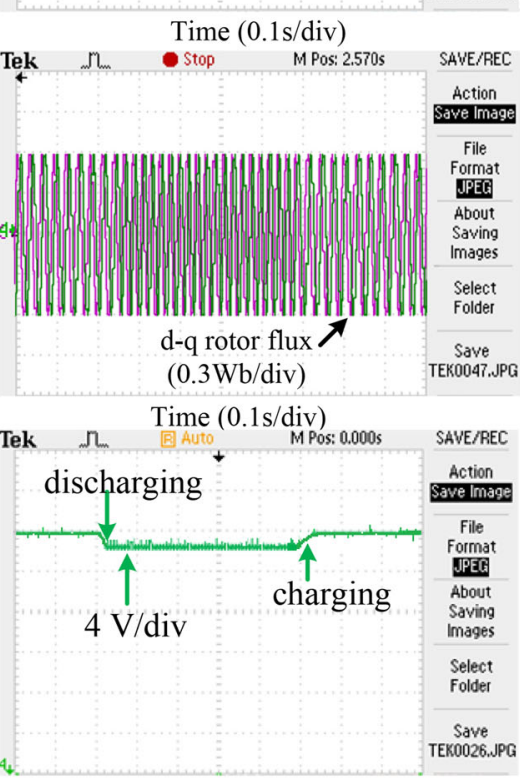

Time $0.1 \mathrm{~s} / \mathrm{div}$

(c)

Figure 18. The experimental load peturbation responses of FBL-controlled motor drive for 50\% step load from 1.5 to $2 \mathrm{~s}$ using (a) PI controller: (i) speed $n_{r}$, (ii) torque $T e$, (iii) stator current $i_{a}$, (iv) rotor $d-q$ flux $\Psi_{d q r}$ and (v) DC-link voltage (Vc); (b) conventional twoinput NFC: (i) $n_{r}$, (ii) $T e$, (iii) $i_{a}$, (iv) $\Psi_{d q r}$ and (v) $V c$ and (c) proposed simplified NFC: (i) $n_{r}$, (ii) $T e$, (iii) $i_{a}$, (iv) $\Psi_{d q r}$ and (v) $V c$.

operating modes as shown in figures 17-20 with the experimental set-up as in figure 9. It is observed that the performance of the proposed simple adaptation of NFC is similar to that of conventional NFC, but it has the advantage of significantly reduced computational weight, which is found to be $100 \mu \mathrm{s}$. The details of the experimental performance under various operating conditions are presented in table 2.

Case 1: Initially, the experimental performance of starting dynamics and forward motoring is obtained at $800 \mathrm{rpm}$ without any load perturbation as illustrated in figure $17 \mathrm{a}-\mathrm{c}$.
The feedback-linearized IM accelerates from rest condition to target speed $800 \mathrm{rpm}$ in $1.38 \mathrm{~s}$ with the overshoot using the PI controller, whereas it smoothly settles at 1.08 and $1.15 \mathrm{~s}$ using the conventional NFC and proposed NFC, respectively. Moreover, the torque ripple of the proposed NFC, like conventional NFC, is remarkably reduced to 0.5 $\mathrm{Nm}$, which improves the torque response significantly as compared with PI controller, where the ripple is found to be $5 \mathrm{Nm}$ as shown in figure 17(ii). The stator current response using all controllers is shown in figure 17(iii). The magnitude of steady-state stator current is less with less 


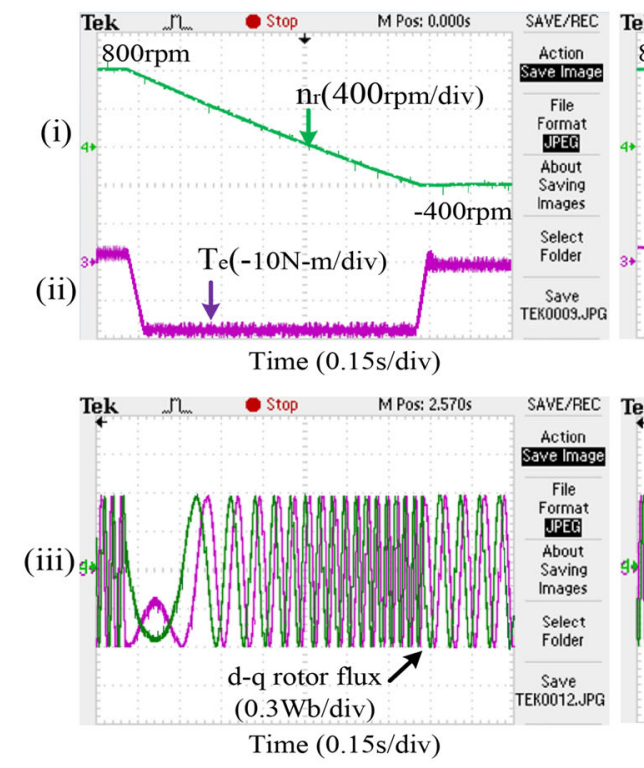

(a)
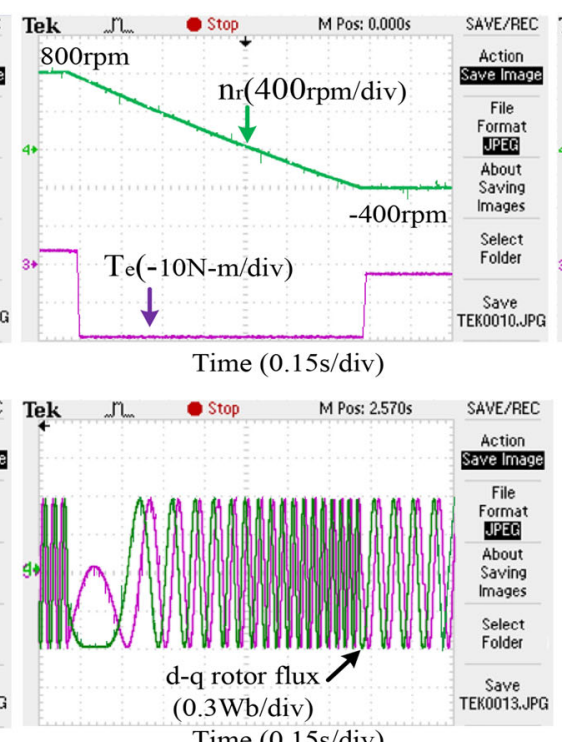

Time $(0.15 \mathrm{~s} / \mathrm{div})$

(b)

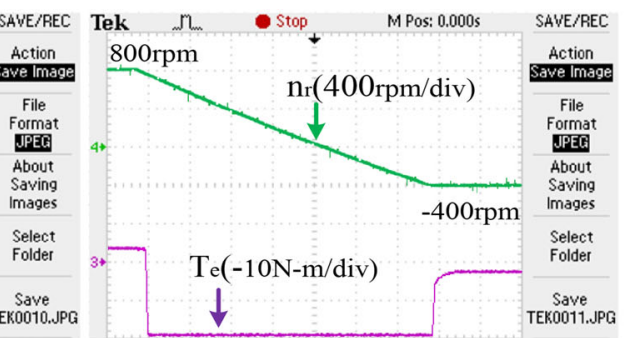

Time $(0.15 \mathrm{~s} / \mathrm{div})$

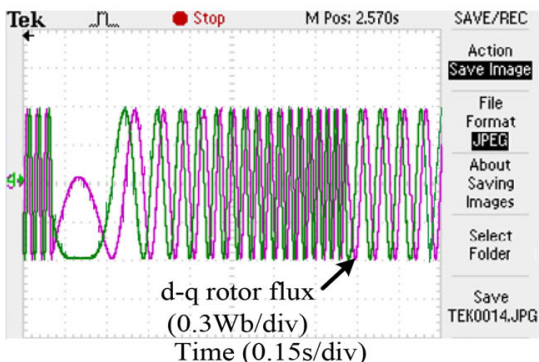

(c)

Figure 19. Experimental reverse characteristics of FBL-based IM drive using (a) PI controller: (i) speed $n_{r}$, (ii) torque $T e$ and (iii) rotor $d-q$ flux; (b) conventional NFC: (i) $n_{r}$, (ii) $T e$ and (iii) rotor $d-q$ flux and (c) proposed NFC: (i) $n_{r}$, (ii) $T e$ and (iii) rotor $d-q$ flux.

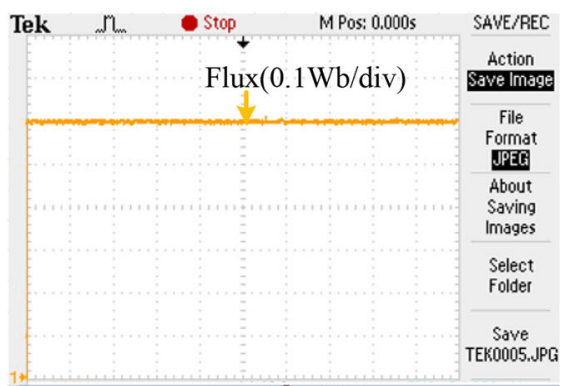

Time( $0.4 \mathrm{~s} / \mathrm{div})$

(a)

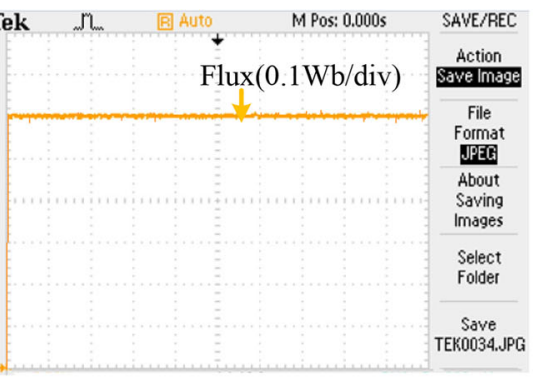

$\operatorname{Time}(0.4 \mathrm{~s} / \mathrm{div})$

(b)

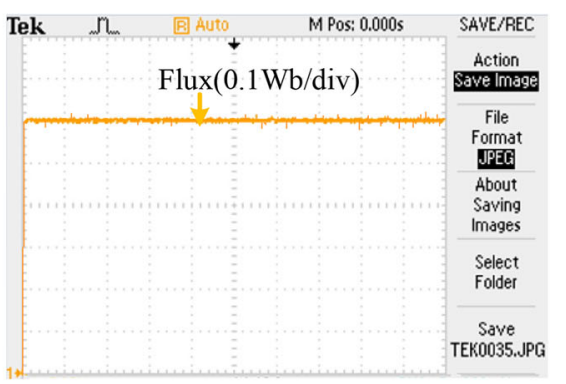

Time(0.4s/div)

(c)

Figure 20. Experimental flux response (starting, step load of 50\% from 1.5 to $2 \mathrm{~s}$ and reverse mode) of FBL-controlled IM for using (a) PI controller, (b) conventional two-input NFC and (c) proposed single-input NFC.

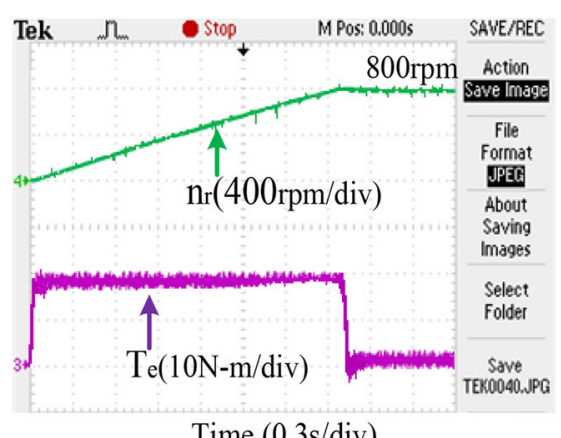

Time $(0.3 \mathrm{~s} / \mathrm{div})$

(a)

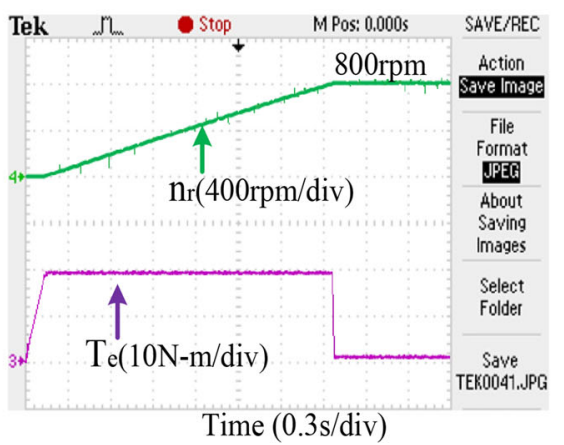

(b)

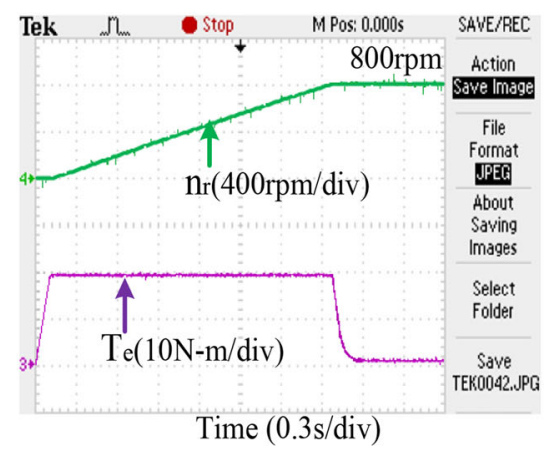

(c)

Figure 21. Experimental starting responses of FBL-controlled IM drive with twice of rotor inertia for (a) PI controller: (i) speed $n_{r}$ and (ii) torque Te; (b) conventional NFC: (i) $n_{r}$ and (ii) $T e$ and (c) proposed NFC: (i) $n_{r}$ and (ii) $T e$. 


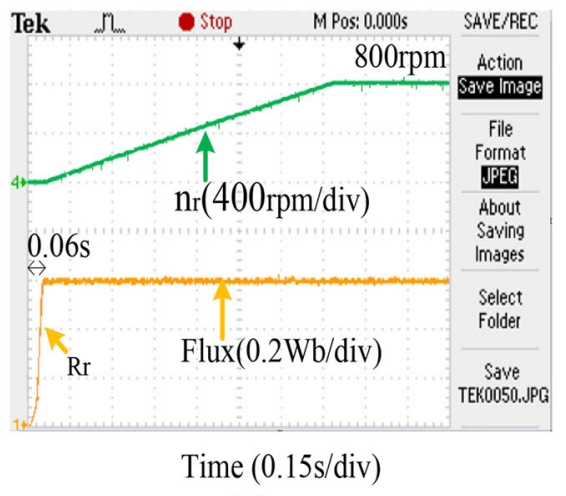

(a)

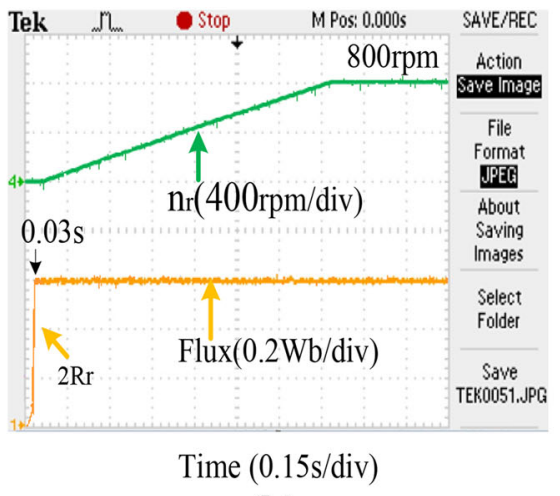

(b)

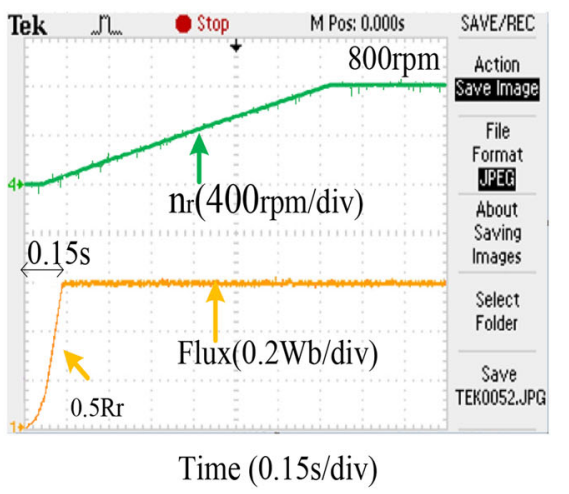

(c)

Figure 22. Experimental start-up characteristics of proposed NFC-based FBL with (a) $R_{r},(\mathbf{b})+100 \% R_{r}$ error and (c) $-50 \% R_{r}$ error.

distortion using the proposed NFC as compared with PIcontroller-based drive. However, the rotor $d-q$ components of flux are observed as a constant magnitude of $\pm 0.6 \mathrm{~Wb}$ from starting to steady-state without losing its decoupling behaviour, which is evident from figure 17(iv).

Case 2: While IM operates at steady-state speed of 800 rpm, a sudden load of $10 \mathrm{Nm}$ is applied and withdrawn at instants 1.5 and $2 \mathrm{~s}$, respectively, as shown in figure 18a. This leads to a speed undershoot and overshoot of $2.16 \mathrm{rpm}$ at the instants mentioned above and settles down at 1.84 and $2.34 \mathrm{~s}$, respectively, using the PI controller. The load perturbation makes the motor current to increase to $12.8 \mathrm{~A}$ at $1.51 \mathrm{~s}$ and decrease down at $2.01 \mathrm{~s}$.

The proposed NFC-based feedback-linearized drive preserves quick and robust response of conventional NFCbased linearized IM drive. Also, there is a remarkable reduction of torque ripple by around $90 \%$, and reduction of speed undershoot/overshoot by $33 \%$ over that of PI-controller-based drive during load perturbation, which is shown in figure 18c(i) and (ii). Apart from this, the settling times of speed during load changes are $0.16 \mathrm{~s}$, which are improved by around $10 \%$ over those of the PI-torque controller. Moreover, the proposed controller-based FBLmodelled IM drive shows less dip (2 V) and less distortion in capacitor voltage (DC-link voltage) during the step load change of $50 \%$ as shown in figure $18 \mathrm{c}(\mathrm{v})$. Nevertheless, the flux components for controllers remain constant throughout the operation, which is evident from figure 18(iv).

Case 3: The subsequent experimental performance in reversal mode of IM is observed in figure 19a-c. The responses of the proposed NFC-based drive resemble those of conventional NFC, and simultaneously show the superiority over PI-controller-based drive. It took place at $2.5 \mathrm{~s}$ with uniform deceleration, reaching command speed of $400 \mathrm{rpm}$ at $3.85,3.55$ and $3.64 \mathrm{~s}$ using PI, conventional NFC and proposed NFC-based drive, respectively, as shown in figure 19(i). Figure 19(ii) also reveals that the distortion in torque is drastically reduced using the proposed NFC-based drive. The rotor flux component is observed to be constant throughout the operations as shown in figure 19(iii).

The flux remains uniform through every working mode regardless of the speed for the various controllers, which is obvious from the results of figure 20. Further, the robustness of the feedback-linearized IM drive with the proposed SNFC is investigated by experiment with the variation of the parameter and the responses are illustrated in figure 21. The parameter rotor inertia was increased by coupling the existing motor with another motor, and it is observed that the rotor takes more time (almost doubled) as compared with figure 17(i) to reach the command value smoothly unlike that with the PI controller as the inertia is doubled.

\section{Sensitivity analysis and robustness studies of controllers}

The experimental response of the closed-loop system under the deviation of the system parameter is studied here and is depicted in figures 21-23. The main objective of this section is to verify the robustness stability, correctness and error sensitivity of the proposed controller-based drive scheme rather than the dynamic behaviour of the response under the conditions mentioned earlier that are confronted when the real-time analysis is carried out. The motor parameters used for execution of the FBL are constant here, and the controller used here is so designed that the system achieves robustness stability as the parameter varies during the operation. The impact of flux and torque error on FBL is not considered here as the torque and flux estimator provides comparatively good results.

Taking into consideration the uncertainties, the errors of the control signals are symbolized as $\Delta i_{d s}^{*}$ and $\Delta i_{q s}^{*}$. Equation (22) is used to evaluate these errors in terms of parameter error and to analyse the impact of uncertainties in the case of NFC design. Hence, Eq. (22) can be written as follows: 


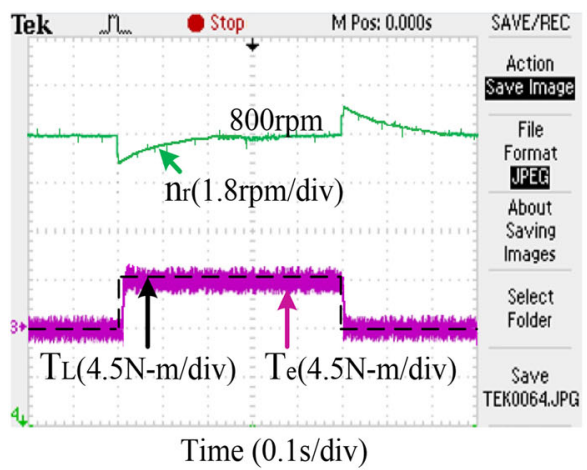

(i)

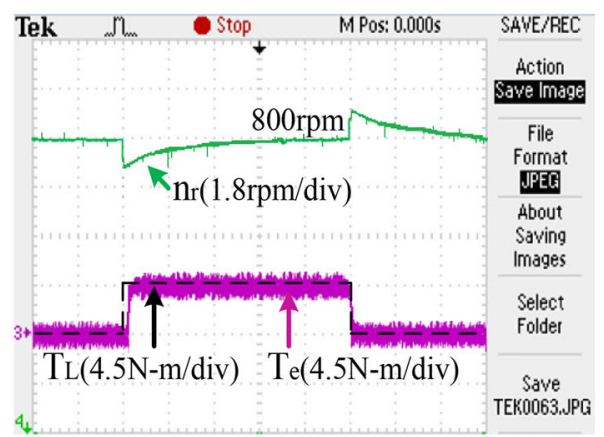

Time (0.1s/div)

(i)

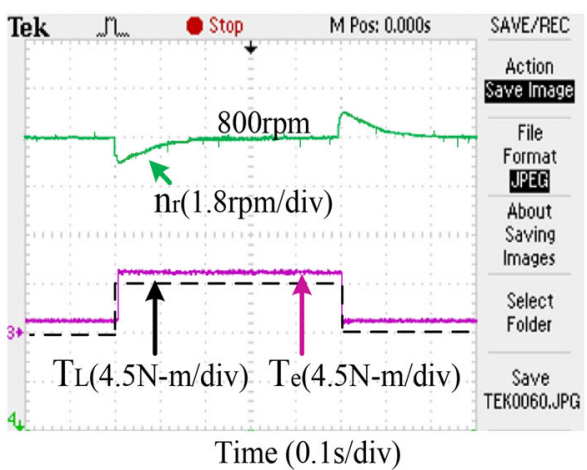

(ii)

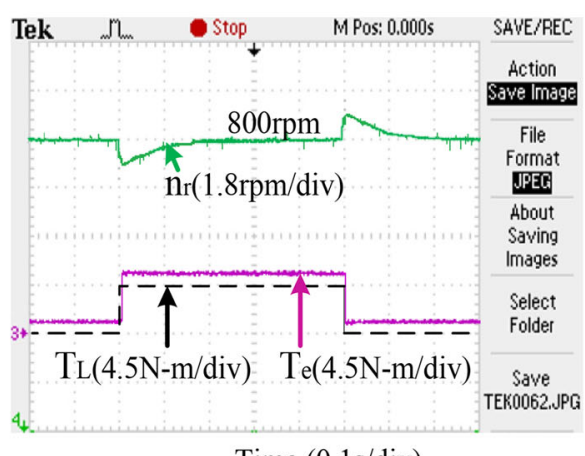

Time (0.1s/div)

(ii)

Figure 23. The experimental load peturbation responses of FBL-controlled motor drive for $4.5 \mathrm{Nm}$ load from 1 to $1.5 \mathrm{~s}$ for different gains of speed PI controller with (a) $K_{p}=20$ and $K_{i}=0.02$ : (i) PI-controller-based drive and (ii) proposed NFC-based drive; (b) $K_{p}=17$ and $K_{i}=0.01$ : (i) PI-controller-based drive and (ii) proposed NFC-based drive.

$$
i_{s}=i_{d s}^{*}+j i_{q s}^{*}=u 1-\frac{u 2}{\psi_{r}} .
$$

Equation (58) can be written in terms of the equivalent error $\Delta u$ as follows:

$$
i_{s}=(u 1+\Delta u 1)-\frac{j}{\psi_{r}}(u 2+\Delta u 2) .
$$

Equations (58) and (59) give the equivalent error $\Delta u$ as

$$
\Delta u=\Delta u 1+j \Delta u 2=-\frac{u 2}{\psi_{r}}+j \frac{u 2}{\psi_{r}} .
$$

Using Eq. (60) and with the errors $(u 1-\Delta u 1)$ and $(u 2-\Delta u 2)$, Eqs. (19) and (20) can be written as follows:

$$
\begin{aligned}
\frac{d \psi_{r}}{d t} & =-\frac{R_{r}}{L_{r}} \psi_{r}+\frac{L_{m} R_{r}}{L_{r}}\left(u 1+\frac{u 2}{\psi_{r}}\right), \\
\frac{d \omega_{r}}{d t} & =-\frac{B}{J} \omega_{r}+\frac{1}{J} \frac{3}{2} \frac{L_{m}}{L_{r}} P 2 u 2-\frac{1}{J} T_{l} .
\end{aligned}
$$

However, $u 2$ is produced by the NFC, and it has no uncertainty. Hence, from Eq. (61), the rotor resistance $R_{r}$ is the most dominant parameter variation as it changes with temperature. However, the proposed FBL has the advantage of not changing the rotor speed dynamics, but it affects the rotor flux dynamics, which is shown in figure 22. It shows that as $R_{r}$ increases, the rate of change of flux increases, i.e., it reaches the steady-state flux faster, which is evident from Eq. (61). The maximum uncertainty of $R_{r}$ considered here is $100 \%$. Further, $R_{r}$ uncertainty dynamics does not change the steady-state behaviour, making the operation robust. Experimentally, rotor resistance is added with the help of a switch.

Equation (62) reveals that the change in rotor inertia $J$ has a substantial impact on speed dynamics as the rate of change of speed is inversely proportional to $J$. This implies that the rotor takes a longer time to settle at target speed. Figure 21 illustrates that with the proposed NFC the motor can track the target speed smoothly unlike PI-controllerbased drive, but the settling time response is almost twice that of the result shown in figure 17(i) as the rotor inertia is doubled.

Further, the robustness of the proposed NFC is also investigated by reducing the load torque to $4.5 \mathrm{Nm}$ for the same time instants of $1.5-2 \mathrm{~s}$. An experimental analysis is performed by altering the gain of the speed-PI controller $\left(K_{p}, K_{i}\right)$ from $(20,0.02)$ to $(17,0.01)$ as shown in figure 23. It reveals that even if the $K_{p}$ and $\mathrm{K}_{i}$ values of the speed-PI 
controller are altered, unlike PI controller as in figure $23 \mathrm{a}(\mathrm{i})$ and $\mathrm{b}(\mathrm{i})$, there is no such difference of speed response in terms of undershoot/overshoot and settling time by NFC-torque-based feedback-linearized drive as presented in figure 23a(ii) and b(ii). Therefore, the proposed NFC provides substantial torque ripple minimization and less dip in speed with quick dynamic response compared with the PI-controller-based drive with deviation of speedPI controller gain. This shows extreme robustness and correctness because the gain of PI controllers is tuned with proper optimization of rule by NFC using the centre-ofgravity method.

Tables 1 and 2 show comparative analysis of the performance of NFC-based linearized IM drive with the conventional PI controller. From table 2, the experimental results are found to be slightly higher than the simulated results because, some constraints like dead band, fluctuation of temperature, hard switching effect, variation of supply, electromagnetic interference phenomena, etc., cannot be ignored in the real-time analysis.

\section{Conclusion}

The proposed NFC incorporated with the intuitive FBLbased IM drive is articulated in this paper. The overall drive system was designed and modelled in MATLAB software and experimentally investigated in real-time hardware setup using DSP TMS320F2812 processor.

The feedback-linearized IM drive with the proposed NFC and NFC with GA proves the robust and fast response with significantly reduced speed and torque ripple over PI controller as far as starting, load perturbation and speed reversal are concerned. Apart from benefits of NFC, the proposed NFC with GA has the advantage of optimal parameters selection obtained through GA. However, the DC-link capacitor voltage is well balanced all through these operations without using any extra controller. Further, the flux responses all through these operations are maintained almost constant. The performance index on integral time absolute error indicates good responses in case of proposed NFC compared with the conventional PI controller.

Further, the adaptability and robustness of the proposed NFC scheme are proved experimentally by changing the gain of the speed-PI controller. Also, the results demonstrate the better response of flux and perfect decoupling obtained when the proposed NFC is implemented. It is concluded from the results that the performance of the proposed SNFC is similar to that of conventional NFC, but it has the benefit of considerably reduced computational burden. The comparative performance analysis by simulation as well as experiment has been carried out under different operating conditions as given in tables 1 and 2. It shows that the proposed NFC scheme provides a robust and excellent performance over PI-controller-based linearized IM without compromising on its decoupling characteristics. Thus, the proposed NFC as torque and speed regulator is found to be suitable for the high-performance industrial applications. Further, some other advanced artificial intelligence methods with the proposed method can be incorporated as an extension work of this article for the optimal performance of IM drive.

\section{Acknowledgement}

I wish to express my sincere gratitude and thanks to Silicon institute of technology, Bhubaneswar for granting me study-leave and providing constant financial support to carry out this work at National institute of technology Rourkela.

\section{Appendix}

\begin{tabular}{|c|c|c|c|}
\hline \multicolumn{4}{|c|}{ Induction motor drive system parameters } \\
\hline 1 & Rated power & $P_{o r}$ & $3.7 \mathrm{~kW}$ \\
\hline 2 & Rated voltage & $V_{L-L}$ & $415 \mathrm{~V}$ \\
\hline 3 & Rated speed & $n_{r}$ & $1445 \mathrm{rpm}$ \\
\hline 4 & Rated frequency & $f_{r}$ & $50 \mathrm{~Hz}$ \\
\hline 5 & No. of pole pairs & $P$ & 2 \\
\hline 6 & Stator resistance & $R_{s}$ & $7.34 \Omega$ \\
\hline 7 & Stator leakage inductance & $L_{l s}$ & $0.021 \mathrm{H}$ \\
\hline 8 & Rotor resistance & $R_{r}$ & $5.64 \Omega$ \\
\hline 9 & Rotor leakage inductance & $L_{l r}$ & $0.021 \mathrm{H}$ \\
\hline 10 & Mutual inductance & $L_{m}$ & $0.5 \mathrm{H}$ \\
\hline 11 & Friction coefficient & $B$ & $\begin{array}{c}0.035 \mathrm{~kg} \\
\mathrm{~m}^{2} / \mathrm{s}\end{array}$ \\
\hline 12 & Inertia coefficient & $J$ & $0.16 \mathrm{~kg} \mathrm{~m}^{2}$ \\
\hline \multicolumn{4}{|c|}{ Controllers parameters } \\
\hline 13 & PI-speed control & $K_{p} / K_{i}$ & 20/0.02 \\
\hline 14 & PI-torque control & $K_{p} / K_{i}$ & $10 / 0.01$ \\
\hline 15 & Tuning rate of the weight & $\eta_{w i}$ & 0.05 \\
\hline 16 & Tuning rate of the MFs & $\eta_{a i} / \eta_{b i}$ & 0.005 \\
\hline 17 & $\begin{array}{l}\text { Sampling time for proposed NFC- } \\
\text { based drive }\end{array}$ & $T_{s}$ & $100 \mu \mathrm{s}$ \\
\hline 18 & $\begin{array}{c}\text { Sampling time for conventional NFC- } \\
\text { based drive }\end{array}$ & $T_{s}$ & $250 \mu \mathrm{s}$ \\
\hline 19 & \multicolumn{3}{|c|}{ For SNFC-GA-based drive } \\
\hline \multicolumn{3}{|c|}{ Population size } & 40 \\
\hline \multicolumn{3}{|c|}{ Crossover rate } & 0.8 \\
\hline \multicolumn{3}{|c|}{ Mutation rate } & 0.18 \\
\hline \multicolumn{3}{|c|}{ Learning rate } & 0.045 \\
\hline \multicolumn{3}{|c|}{ Coefficient of momentum } & 0.55 \\
\hline
\end{tabular}

\section{References}

[1] Slotine J J E and Li W 1991 Applied nonlinear control. Englewood Cliffs: Prentice-Hall

[2] Bose B K 2008 Modern power electronics and AC drives. New Delhi: Prentice-Hall of India 
[3] Blaschke F 1972 The principle of field orientation as applied to the new Transvector closed-loop control system for rotating-field machines. Siemens Rev. 39: 217-220

[4] Kim G S, Ha I J and Ko M S 1992 Control of induction motors for both high dynamic performance and high power efficiency. IEEE Trans. Ind. Electron. 39(4): 323-333

[5] Isidori A, Krener A J, Gori-Giorgi C and Monaco S 1981 Nonlinear decoupling via feedback: a differential-geometric approach. IEEE Trans. Autom. Control 26: 331-345

[6] Krezminski Z 1987 Nonlinear control of induction motor. In: Proceedings of the 10th IFAC World Congress on Automatic Control, vol. 3, pp. 349-354

[7] Charlet B, Levine J and Marino R 1988 Two sufficient conditions for dynamic feedback linearization. In: Analysis and Optimization of Systems. Lecture Notes in Control and Information Sciences, vol. 111

[8] Chiasson J 1993 Dynamic feedback linearization of the induction motor. IEEE Trans. Autom. Control 38: 1588-1594

[9] Chiasson J 1998 A new approach to dynamic feedback linearization control of an induction motor. IEEE Trans. Autom. Control 43(3): 391-397

[10] Luckjiff G, Wallace I and Divan D 2001 Feedback linearization of current regulated induction motors. In: Proceedings of IEEE PESC, pp. 1173-1178

[11] Chaoying X and Haiyu G 2015 Feedback linearization control approach for brushless doubly-fed machine. Int. J. Precis. Eng. Manuf. 16(8): 1699-1709

[12] Lee C C 1990 Fuzzy logic in control systems: fuzzy logic controlle-part 2. IEEE Trans. Syst. Man Cybern. 20(2): 404-418

[13] Mir S A, Zinger D S and Elbuluk M E 1994 Fuzzy controller for inverter fed induction machines. IEEE Trans. Ind. Appl. 30(1): 78-84

[14] Utkin V, Guldner J and Shi J 1999 Sliding mode control in electromechanical systems. London: Taylor \& Francis

[15] Lascu C, Boldea I and Blaabjerg F 2004 Variable-structure direct torque control-a class of fast and robust controllers for induction machine drives. IEEE Trans. Ind. Electron. 51(4): 785-792

[16] Karakas E and Vardarbasi S 2007 Speed control of SR motor by self-tuning fuzzy PI controller with artificial neural network. Sadhana 32(5): 587-596

[17] Mahfouz A A, Sarhan G M and Nafeh A A 2005 Microcontroller implementation of direct torque control. Int. J. Numer. Model. 18: 85-94

[18] Kazmierkowski M P and Sobczuk D 1996 Sliding mode feedback linearization of PWM inverter fed induction motor. In: Proceedings of IEEE IECON, vol. 1, pp. 244-249

[19] Swain S D, Ray P K and Mohanty K B 2016 Improvement of power quality using a robust hybrid series active power filter. IEEE Trans. Power Electron. 32(5): 3490-3498

[20] Sobczuk D L 2014 Some aspects of nonlinear and discontinuous control with induction motor application. In: $A d$ vanced and Intelligent Control in Power Electronics and Drives, vol. 531, pp. 375-407

[21] Uddin M N and Wen H 2007 Development of a self-tuned neuro-fuzzy controller for induction motor drives. IEEE Trans. Ind. Appl. 43(4): 1108-1116

[22] Grabowski P Z, Bose B K and Blaabjerg F 2000 A simple direct-torque neuro-fuzzy control of PWM-inverter-fed induction motor drive. IEEE Trans. Ind. Electron. 47(4): 863-870
[23] Venkataramana Naik N and Singh S P 2015 A comparative analytical performance of F2DTC and PIDTC of induction motor using DSPACE DS-1104. IEEE Trans. Ind. Electron. 62(12): 7350-7359

[24] Ramesh T and Panda A K 2015 Type-2 fuzzy logic control based MRAS speed estimator for speed sensorless direct torque and flux control of an induction motor drive. ISA Trans. 57: 262-275

[25] Uddin M N, Abido M A and Rahman M A 2004 Development and implementation of a hybrid intelligent controller for interior permanent magnet synchronous motor drive. IEEE Trans. Ind. Appl. 40(1): 68-76

[26] Chang G W, Espinosa-Perez G, Mendes E and Ortega R 2000 Tuning rules for the PI gains of field-oriented controllers of induction motors. IEEE Trans. Ind. Electron. 47(3): 592-602

[27] Uddin M N and Chy M I 2010 A novel fuzzy logic controller based torque and flux controls of IPM synchronous motor. IEEE Trans. Ind. Appl. 46(3): 1220-1229

[28] Mishra R N and Mohanty K B 2015 Performance enhancement of a linearized induction motor drive using ANFIS based torque controller. In: Proceedings of the 12th India International Conference (INDICON), pp. 1-6

[29] Mishra R N and Mohanty K B 2016 Real time implementation of an ANFIS-based induction motor drive via feedback linearization for performance enhancement. Eng. Sci. Technol. Int. J. 19: 1714-1730

[30] Rubaai A, Jerry J and Smith S T 2011 Performance evaluation of fuzzy switching position system controller for automation and process industry control. IEEE Trans. Ind. Appl. 47(5): 2274-2282

[31] Tang Z R, Bai B and Xie D 2010 Novel direct torque control based on space vector modulation with adaptive stator flux observer for induction motors. IEEE Trans. Magn. 46(8): 3133-3136

[32] Duan X, Deng H and Li H 2013 A saturation-based tuning method for fuzzy PID controller. IEEE Trans. Ind. Electron. 60(11): 577-585

[33] Jang J S R 1993 ANFIS: adaptive-network-based fuzzy inference system. IEEE Trans. Syst. Man Cybern. 23(3): 665-685

[34] Alexandridis A, Chondrodima E and Sarimveis H 2016 Cooperative learning for radial basis function networks using particle swarm optimization. Appl. Soft Comput. 49: 485-497

[35] De A, Krishna V, Mamanduru R, Gunasekaran A, Subramanian N and Tiwari M K 2016 Composite particle algorithm for sustainable integrated dynamic ship routing and scheduling optimization. Comput. Ind. Eng. 96: 201-215

[36] Soleimani H and Kannan G 2015 Hybrid particle swarm optimization and genetic algorithm for closed-loop supply chain network design in large-scale networks. Appl. Math. Model. 39: 3990-4012

[37] Igoulalene I, Benyoucef L and Tiwari M K 2015 Novel fuzzy hybrid multi-criteria group decision making approaches for the strategic supplier selection problem. Expert Syst. Appl. 42: 3342-3356

[38] Maiyar L M, Thakkar J J, Awasthi A and Tiwari M K 2015 Development of an effective cost minimization model for food grain shipments. IFAC-PapersOnLine 48(3): 881-886

[39] Panda S and Padhy N P 2008 Comparison of particle swarm optimization and genetic algorithm for FACTS-based controller design. Appl. Soft Comput. 8: 1418-1427 
[40] Changyu S, Lixia W and Qian L 2007 Optimization of injection molding process parameters using combination of artificial neural network and genetic algorithm method. $J$. Mater. Process. Technol. 183: 412-418

[41] Uddin M N, Huang Z R and Siddique Hossain A B M 2014 Development and implementation of a simplified self-tuned neuro-fuzzy-based IM drive. IEEE Trans. Ind. Appl. 50(1): 51-59

[42] Hafeez M, Uddin M N, Rahim N A and Ping H W 2014 Selftuned NFC and adaptive torque hysteresis-based DTC scheme for IM drive. IEEE Trans. Ind. Appl. 50(2): $1410-1420$

[43] Durgasukumar G and Pathak M K 2012 Comparison of adaptive neuro-fuzzy based space vector modulation for twolevel inverter. Int. J. Electr. Power Energy Syst. 38(1): 9-19
[44] Venkataramana Naik N, Thankachan J and Singh S P 2016 A neuro-fuzzy direct torque control using bus-clamped space vector modulation. IETE Tech. Rev. 33(2): 205-217

[45] Venugopal K P, Sudhakar R and Pandya A S 1995 An improved scheme for direct adaptive control of dynamical systems using back propagation neural networks. J. Circuits Syst. Signal Process. 14(2): 213-236

[46] Lin F J, Huang P K and Chou W D 2007 Recurrent-fuzzyneural-network-controlled linear induction motor servo drive using genetic algorithms. IEEE Trans. Ind. Electron. 54(3): 1449-1461

[47] Astrom K J and Hagglund T 1995 PID controllers: theory, design, and tuning, 2nd ed. Instrument Society of America, The International Society for Measurement and Control, p. 166 